\title{
Bacterial-Based Methods for Cancer Treatment: What We Know and Where We Are
}

Foad Rommasi (D)

Received: September 23, 2021 / Accepted: October 25, 2021 / Published online: November 15, 2021

(C) The Author(s) 2021

\begin{abstract}
A severe disease, cancer is caused by the exponential and uncontrolled growth of cells, leading to organ dysfunction as well as disorders. This disease has been recognized as one of the significant challenges to health and medicine. Various treatment procedures for cancer are associated with diverse side effects; the most conventional cancer treatments include chemotherapy, surgery, and radiotherapy, among others. Numerous adverse and side effects, low specificity and sensitivity, narrow therapeutic windows, and, recently, the emergence of tumor cells resistant to such treatments have been documented as the shortcomings of conventional treatment strategies. As a group of prokaryotic microorganisms, bacteria have great
\end{abstract}

F. Rommasi ( $\square)$

Faculty of Life Sciences and Biotechnology, Shahid

Beheshti University, Tehran, Iran

e-mail: f.ramasi@mail.sbu.ac.ir

F. Rommasi

Microbiology Research Center (MRC), Pasteur

Institute of Iran, Tehran, Iran potential for use in cancer therapy. Currently, utilizing bacteria for cancer treatment has attracted the attention of scientists. The high potential of bacteria to become non-pathogenic by genetic manipulation, their distinguished virulence factors (which can be used as weapons against tumors), their ability to proliferate in tissues, and the contingency to control their population by administrating antibiotics, etc., have made bacteria viable candidates and live micro-medication for cancer therapies. However, the possible cytotoxicity impacts of bacteria, their inability to entirely lyse cancerous cells, as well as the probability of mutations in their genomes are among the significant challenges of bacteria-based methods for cancer treatment. In this article, various available data on bacterial therapeutics, along with their pros and cons, are discussed.

Keywords: Bacterial Bacteriotherapy;

Cancer

therapeutics;

Immunotherapy; Microbial treatment; Multimodal therapies metabolites; 


\section{Key Summary Points}

The present review study was carried out to summarize the most recent data available on bacteria-based methods for cancer treatment to prepare a comprehensive basis for future research

Multiple side effects of available and conventional cancer treatment methods and emergence of resistant tumor cells have highlighted the importance of ingenious strategies for cancer therapy

Low specificity and sensitivity, a narrow therapeutic window, and high cellular toxicity of available cancer treatment methods have increased the importance of novel procedures like bacteriotherapy

The suitable properties of bacteria and their metabolites, such as their high potential for genomic or biochemical manipulation, etc., have made them a suitable candidate for cancer treatment

In conclusion, some microbial metabolites and bacteria have demonstrated remarkable antitumor impacts and can be used as novel approaches for cancer treatment solely or in combined therapies

\section{INTRODUCTION}

Having serious complications, cancer is a severe and critical disease that causes many deaths every year worldwide. Scientists are concerned about the growing rate of cancer. From a medical point of view, cancer can be defined as the unregulated and invasive proliferation of transformed cells. These neoplastic cells have the potential to disperse to various tissues and organs in the body via the metastatic process. According to a recent World Health Organization (WHO) report, cancer is the first, or at least second, cause of death in people under the age of 70 years in 112 out of 183 countries [1].
While lung, prostate, gastric, colon, and liver cancers are the prevailing cancers in males, breast, lung, colon, uterus, and thyroid cancers are the most prevalent in females. Inducing apoptosis and preventing the growth and proliferation of tumor cells have been the mainstays of cancer treatment so far [2]. Although the standard antitumor therapy methods, including surgery and tumor resection, radiotherapy, and chemotherapy, have been efficient and valuable in treating and improving most symptoms, they remain ineffective for nearly half of cancer cases. Therefore, alternative cancer treatments are being developed to target tumors and cancerous tissues more efficiently [3].

Currently, scientists are investigating and developing novel strategies for treating cancer [4]. Nevertheless, precise examination and modifications in these methods are required for selecting the best alternative therapies and using them in cancer treatment [5]. Thus, particular pioneer therapeutic approaches, like immunotherapy, stem cell-based treatment, hormone therapy, and dendritic cell-based immunotherapy, have recently been implemented. As a conventional and widely exploited treatment strategy against tumors, chemotherapy can be practical in concomitantmultimodal therapies. However, it may also result in the appearance of multidrug-resistant (MDR) malignant cells and metastasis in some patients [6]. Therefore, there is a tremendous demand for up-to-date cancer treatment methods and remedial substances with fewer adverse and side effects and higher efficiency. In the last 10 years, scientists and researchers have explored bacteria and their metabolites' potential in tumor cell destruction as a novel antineoplastic strategy. They have found that bacteria and their products not only have low toxicity, but also have limited side effects on normal and healthy cells. Some bacterial species in various forms and bacterial metabolites (including peptides, bacteriocins, etc.) have been utilized to treat cancer patients. The results have demonstrated that these agents can selectively multiply and influence tumors and restrain their growth [7]. In anticancer bacteriabased immunotherapy methods, the used 


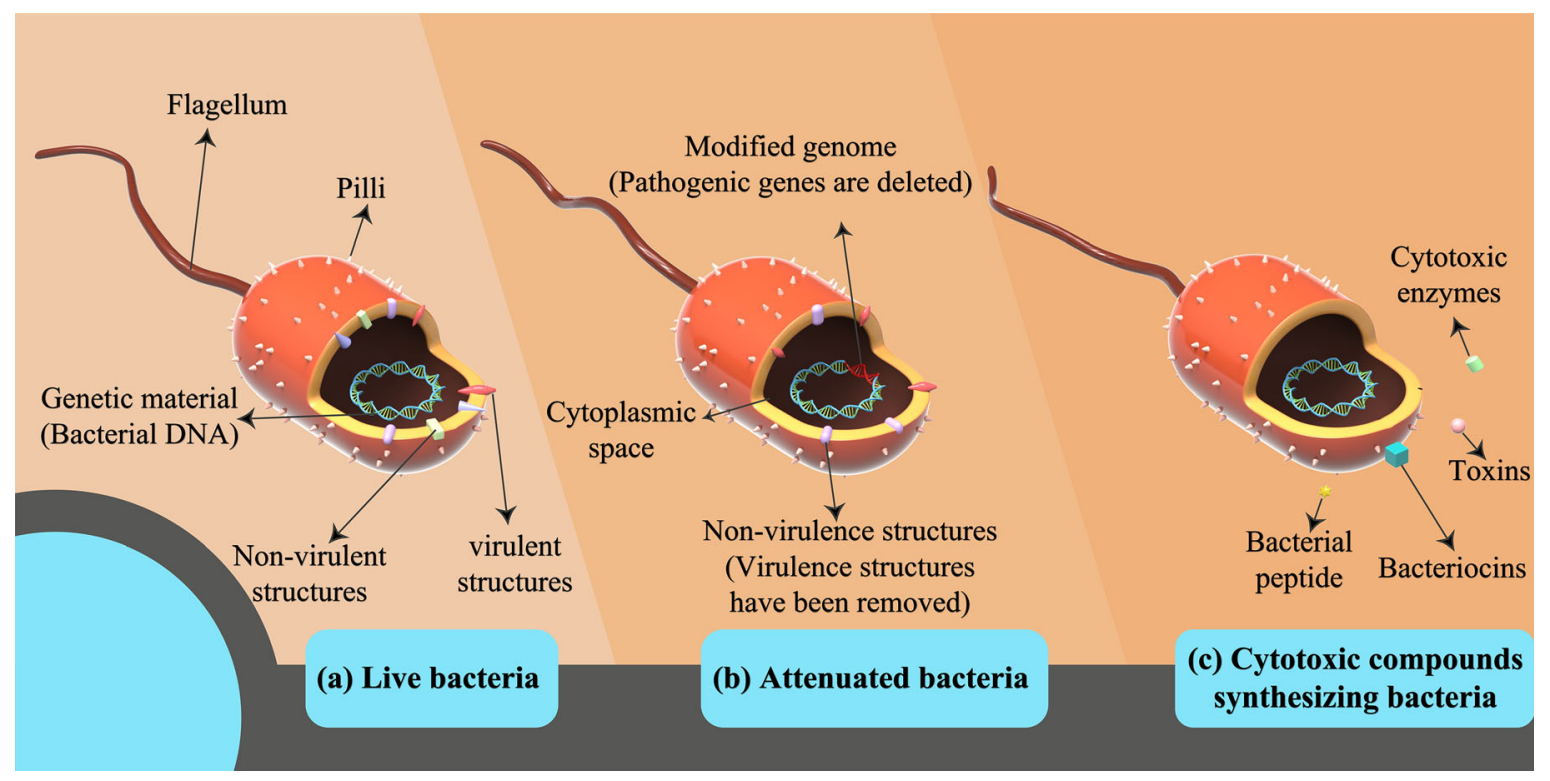

Fig. 1 Bacteria in the living form (a), attenuated (b), or their metabolites (c) can be used for cancer therapy. The pathogenic bacteria may turn into non-pathogenic and appropriate weapons for cancer treatment by deleting a part of their genome or virulent structures bacteria can be present in living or attenuated conditions, or even in genetically engineered forms, as illustrated in Fig. 1.

Adopting bacteria for cancer treatments has been associated with promising outcomes in diverse cases. Spores of anaerobic bacteria can be utilized to synthesize, develop and produce anticancer agents. They may also be used as carriers for gene and drug delivery to tumor tissues. These bacterial spores can obtain hypoxic-necrotic tissues, where they are able to germinate, multiply, and exert their antitumor function. The application of genetically modified bacteria to selectively destroy tumors and alter cellular enzymes expression has also been accompanied by successful outcomes [8].

Although other microorganisms such as Neospora caninum have also been observed to have anticancer properties, the current study has concentrated on the bacteria-based methods for cancer therapy [9]. Overall, this article has been carried out to gather and summarize the most recent available data and literature on bacteria-based methods for cancer treatment because of the importance of reviewing and investigating these novel strategies. The study aims to create a reliable basis for researchers and their future research by rendering a comprehensive summary of clinical trials on bacteriotherapy and the scientific history of this procedure. This article is based on previously conducted studies and does not contain any new studies with human participants or animals performed by any of the authors.

\section{DISCUSSION}

Apart from briefly reviewing the history and literature of bacteriotherapy, the present study also discusses the bacterial species that can be effective in bacterial immunotherapy. These bacteria and their metabolites can eliminate the tumor tissues from the body and interrupt the growth of neoplastic cells. Moreover, certain bacteria such as Clostridium spp. and 
Bifidobacterium longum strains-which can endure and progress in hypoxic conditionscan proliferate and surround the tumor, causing tumor destruction $[7,10]$.

\section{The Scientific History of Bacteriotherapy: First Observations and Experiments}

The first observations about the effect of bacteria on cancer date back to 150 years ago [11]. At that time, two physicians from Germany, namely W. Busch [12] and F. Fehleisen [13], individually observed the improved symptoms of cancer in patients who accidentally had been infected by erysipelas. Therefore, as the first physician who observed this phenomenon, Busch inoculated erysipelas-causing bacteria in a cancer patient and monitored him for a while [12]. A few years later, Fehleisen identified the cause of erysipelas infection after repeating the experiment and discovered that the Streptococcus pyogenes pathogen causes it [13].

The first official examination on utilizing bacteria for cancer treatment was performed during the past 2 centuries. William Coley, a medical doctor in New York City, developed a combination of two bacteria consisting of $S$. pyogenes and Bacillus prodigiosus (nowadays known as Serratia marcescens) in 1893. He combined the lytic compounds of these bacteria and named the product Coley toxin. He found that the injection of Coley toxin into the cancerous tissues in some patients ceased tumor growth and subsequently improved the patient's healing process [14]. After initial examinations by Coley, certain anaerobic bacterial species, such as those classified as Clostridium spp., were discovered by scientists. These bacteria could reduce oxygen pressure and cause oxygen deprivation in cancerous tissues as they grew, thereby making a hypoxic environment in which the tumor cells died.

BCG vaccine is possibly the most famous bacteria-based agent used for cancer treatment. Caused by Mycobacterium tuberculosis, tuberculosis (TB) is an infectious disease which generally infects the lungs, but it can also harmfully affect other parts of the body $[15,16]$. Bacillus Calmette-Guérin (BCG) vaccine, named after its inventors, is mainly injected into babies intramuscularly to prevent TB infection $[17,18]$. A live attenuated strain of $M$. bovis-which belongs to the same genus as $M$. tuberculosis, but is a different species [18]-is used for BCG vaccine manufacture. It is primarily administered for TB prevention and can be 0 to $80 \%$ effective according to the geography and the laboratory where it is synthesized [19]. However, it has been demonstrated that BCG can be effective in preventing other infections such as Buruli ulcer [20] and treating non-muscle invasive bladder cancer (NMICB) [21]. However, M. bovis was the first bacterium that underwent manipulation to become non-pathogenic. After applying modifications, BCG was administered intravesically to patients who suffered from NMIBC [22]. The intravesical injection of BCG in patients with NMIBC leads to a dramatic decrease in cancer relapse [23]. The primary action mechanism of the BCG vaccine for NMICB treatment is thought to be due to innate and acquired immunity activation by this agent [24] .It has been further elaborated that BCG is able to activate the caspase- 8 signaling pathway, which concerns Toll-like receptor 7 (TLR7), and results in tumor cell apoptosis [25]. It is also reported that BCG can directly cause cell necrosis and death [24]. The other action mechanism of BCG is related to its effects on immune cells. BCG can act as a pathogen-associated molecule pattern (PAMP) and activate pattern recognition receptors (PRR) present in the immune cells $[26,27]$, which ultimately results in the production of cytokines and the activation of the immune system against tumor cells [24, 28]. BCG is also capable of influencing natural killer cells (NK cells) and neutrophils, which can eliminate cancerous cells by phagocytosis or other mechanisms $[24,29]$. BCG can inhibit the cellular proliferation of tumor cells as well $[30,31]$. The summarized history of bacteriotherapy-related observations and studies is shown in Fig. 2.

Nonetheless, it is now well established that numerous bacteria are associated with tumor promoters and carcinogens. It has also been reported that some of them can play a beneficial role in cancer therapy. Some bacterial species, including Clostridia, Shigella, Lactococcus, 


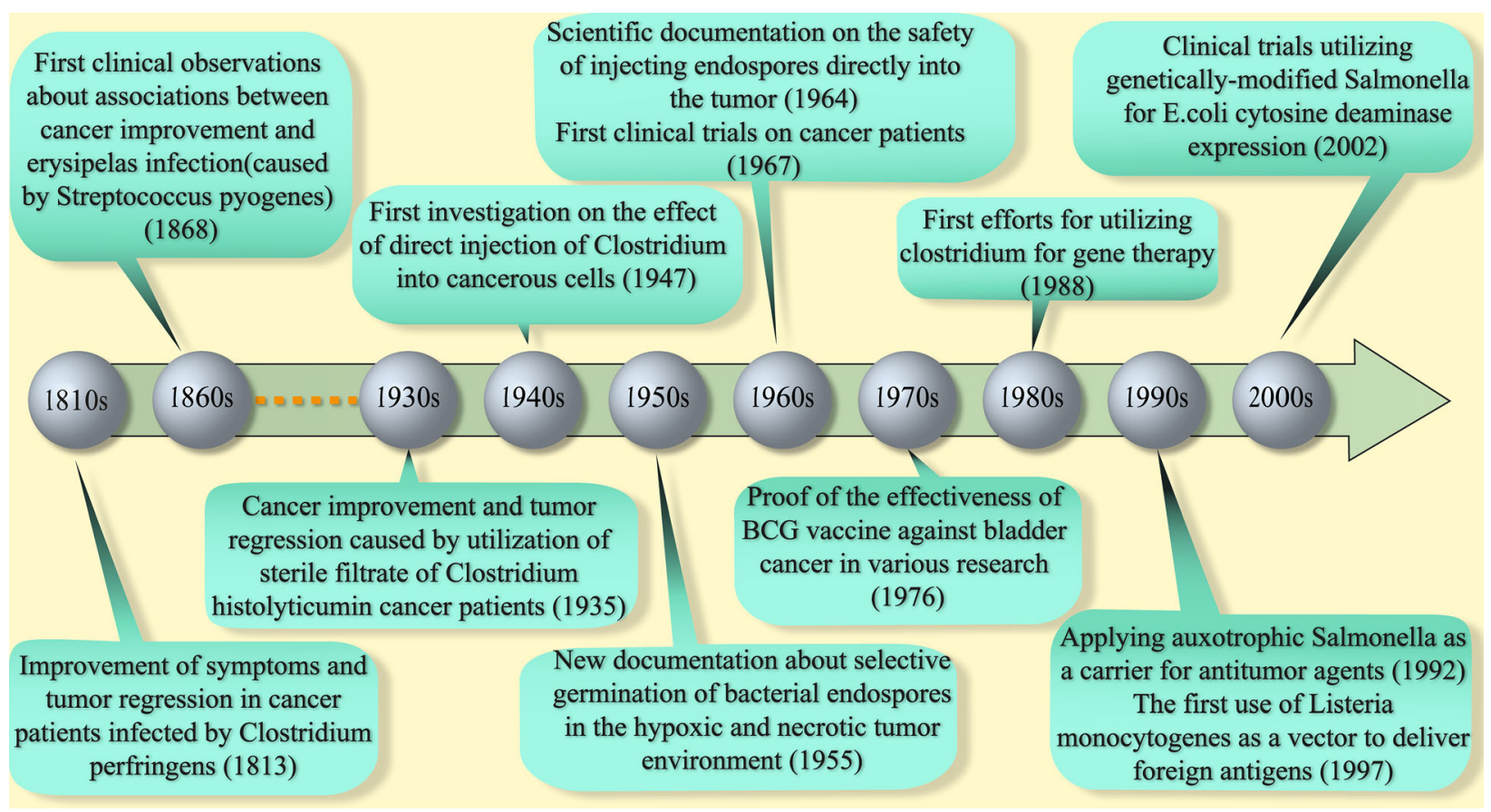

Fig. 2 The history and early observations on the bacteriabased methods for cancer treatment: the first evidence of relationships between bacteria and cancer was accidentally observed and recorded about 2 centuries ago. Since then,

Bifidobacteria, Listeria, Salmonella, Vibrio, and Escherichia coli, have been indicated to have exceptional potential to be used for cancer treatment. They also appear to have a potent tumoricidal effect [32-35].

\section{The Possible Effect of Bacteriotherapy on Immune Cells for Cancer Treatment}

Although bacterial infections are mainly thought to be tumor-promoting-and some of them are even carcinogenic [36]-mounting scientific evidence suggests that some bacterial species can have antitumor effects, as mentioned previously. The interconnection of host cells with bacteria (commensal or pathogenic species) can improve the host's immune response to malignant cells. Tumor cells may impair the immune system's ability to fight diseases, but some bacteria may positively affect it. It is worth noting that immune cells' ability is irrespective of bacterial infections [37, 38]; however, bacteria can positively enhance many studies, examinations, and clinical trials have been performed to enhance bacteriotherapy's effectiveness for cancer therapy

immune cells. The most crucial members of the immune system that have a significant impact on suppressing malignant and abnormal cells are CD8 + T-lymphocytes, macrophages, NK cells, dendritic cells (DCs), and regulatory $\mathrm{T}$ cells (T-regs), which contain FOXP3 as a biomarker. All of the mentioned cells have a remarkable effect on inhibiting the replication of cancerous cells and attacking as well as eliminating them [37]. CD8 + T-cells have been recognized as the most influential immune system components in inhibiting malignant cells growth [39].

Certain microbial infections and complications such as E. coli-induced infections can be used to suppress the tumor tissues. These induced infections improve and accelerate the differentiation of CD8 + killer T-cells, resulting in IFN- $\gamma$ synthesis and an increase in the expression of major histocompatibility complex subtype I (MHC-I) on cancerous cells. This integrative mechanism can ultimately change CD8 + T-cell diapedesis into tumor tissue [39]. 
It should be added that the role of CD8 + T cells in attacking tumor cells is recognized independently from the bacterial activity, and these cells are able to attack cancerous tissues even in the absence of bacterial infections or activities [38]. However, bacterial activities can only enhance their effectiveness. Furthermore, other microbe-related compounds can also affect the CD8 + T-cells. For instance, a study conducted by Diwakar Davar et al. [40] indicated that the administration of responder-derived fecal microbiota transplant (R-FMT) with pembrolizumab can improve the $\mathrm{CD} 8+\mathrm{T}$ cells' induction, reduce IL-8 synthesis, and thus strengthen the immune responses against tumor cells resistant to anti-PD-1 [40].

Another anticancer function of different bacteria and their products is improving the body's immunity against malignant cells. They can counteract cancer cells in multiple ways; the most noticeable of these mechanisms are as follows: (1) consuming and reducing a large amount of needed nutrients for cancer cell metabolism in the tumor environment; (2) being capable of generating and proliferating in necrotic regions creating hypoxic conditions for neoplastic cells; (3) having the potential to be used as a means for delivering anticancer drugs; (4) killing malignant cells by forming biofilms and surrounding them [41-46]. Furthermore, bacteria can be effective in cellular apoptosis through other mechanisms such as hosting and consuming free foreign DNA as well as improving their ability in cancer treatment and tumor elimination [47]. The most important strategies of utilizing bacteria to overcome the restrictions and side effects of conventional cancer treatment methods (e.g., chemotherapy, surgery, radiotherapy, etc.) are illustrated in Fig. 3.

Bacteria also have numerous influences on other immune cells, which are involved in tumor suppression. As cancer cells form and begin to grow, a large number of leukocytes, tumor-associated neutrophils (TANs), myeloidderived suppressor cells (MDSCs), tumor-associated macrophages (TAMs), tyrosine kinase receptor (TIEs)-2-expressing monocytes, and tolerogenic dendritic cells (TDCs) migrate to the cancerous region, improving the density of such cells in that area [48]. Diapedesis of monocytes in response to chemokines and adsorbent chemicals released by tumor cells occurs in the tumor microenvironment. Compounds like colony-stimulating factor 1 (CSF1) and (C-C motif) ligand 2 (CCL2) chemokine are among the substances that absorb monocytes and cause their differentiation into macrophages [49]. As a group of activated immune cells contributing to tissue regeneration, these monocytes are named M2-type macrophages. After being converted to M2 macrophages, these monocytes express and secrete immune inhibitory molecules such as arginase-1 (Arg1) and interleukin 10 (IL-10) cytokine. M2 macrophages suppress host antitumor immune responses, resulting in the formation of malignant cells and tumors. Unlike M2 macrophages, M1 macrophages, also recognized as normal active macrophages or classical killers, express an enzyme called nitric oxide synthase 2 (NOS2), leading to tumor death. They exert their antitumor effect by expressing tumor necrosis factor-alpha (TNF- $\alpha$ ) or other cytokines [50-52]. The effects of bacteriotherapy on immune cells involved in anticancer activities, such as MDSCs, tumor-associated lymphoid cells (TALCs), TAMs, and T-reg cells, are demonstrated in Fig. 4.

Induction of immune responses by bacteria and bacterial immunotherapy has been regarded as an emerging cancer treatment method. This therapeutic technique may have a high chance of breaching the immune barriers caused by conventional immunotherapy, such as immune-related adverse events (irAEs), which are associated with the immune checkpoint inhibitors (ICIs) [53, 54]. ICIs are a drug family that block a particular type of proteins called immune checkpoints, which are expressed by some immune cells like T-cells [55]. These immune checkpoints such as PD-1/PD-L1 and CTLA-4 prevent the overactivation of immune cells and restrain strong responses which are harmful [56, 57]. ICIs block these checkpoints and result in robust immune responses to the cancerous tissues. However, they may also cause adverse side effects such as rash, pruritus, diarrhea, and colitis, which are usually counted as irAEs [53]. Immunotherapy is also capable of eliciting an immune system 


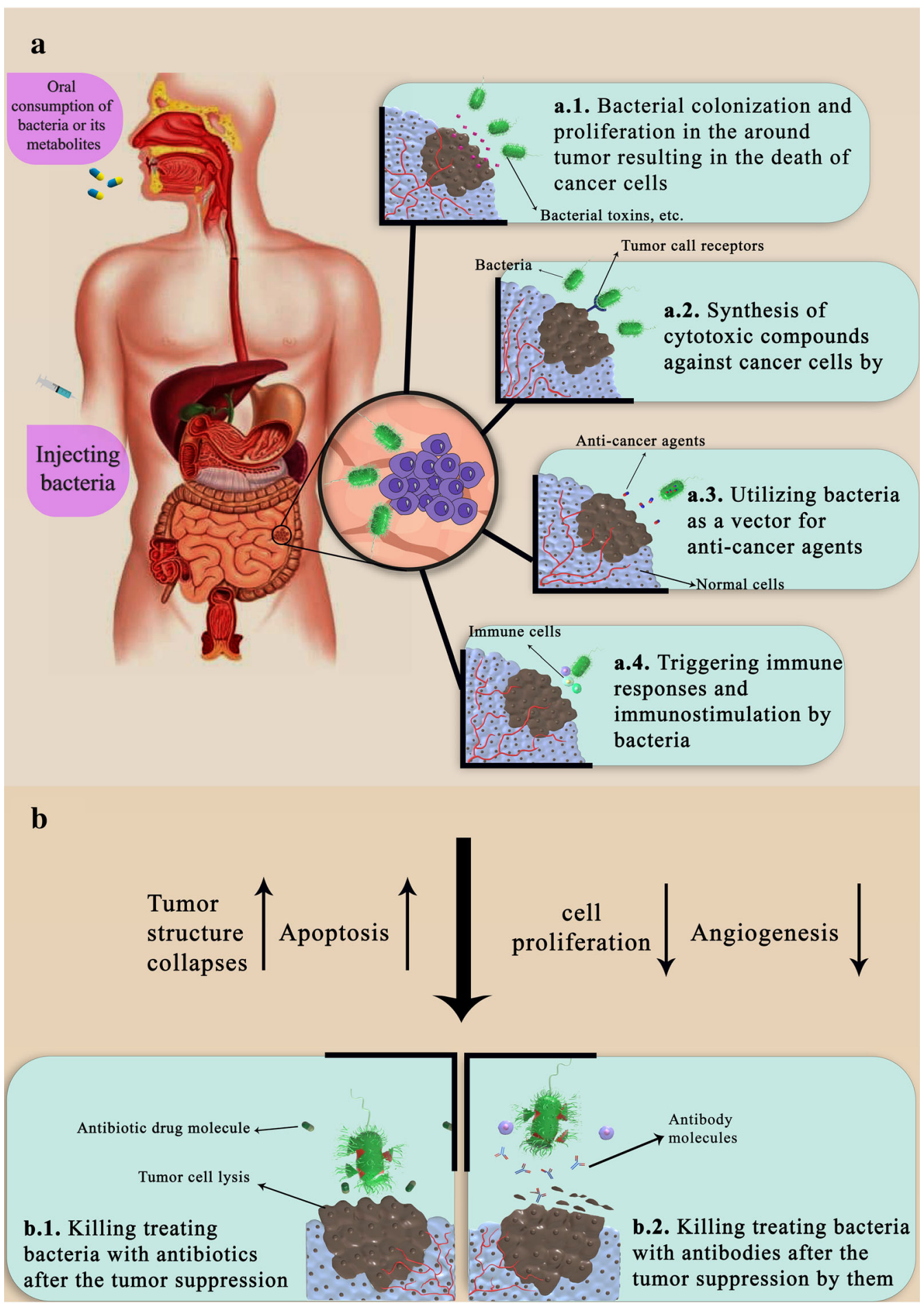


4Fig. 3 The most important usages of bacteria for cancer treatment. Bacteria can bind to cancer cells through their surface ligands and colonize and proliferate there, thereby reducing the available oxygen pressure, which consequently leads to cancer cell destruction (a.1). Synthesis of cytotoxic compounds by bacteria against the cancer cells in the tumor microenvironment after colonization (a.2). Using bacteria as carriers of anticancer agents to increase their specificity (a.3). Stimulation of immune cells to eliminate tumors by bacteria colonized in the tumor microenvironment (a.4). One of the benefits of utilizing bacteria for cancer therapy is the ability to limit them when needed. Bacteria can be eliminated indirectly by triggering and strengthening the immune system (actively or passively) (b.1) or directly with antibiotics (b.2) after cancer treatment

response to tumor cells with limited side effects [58]. The basic idea of immunotherapy is to enhance and strengthen patients' immune systems and make them able to destroy cancer cells. In fact, although scientists recognized the link between the immune system and various diseases a long time ago, they did not explicitly know how the immune system suppresses and affects tumors [59]. Nevertheless, to ward off several infectious diseases and cancers [60], many vaccines have been developed using weakened (such as BCG vaccine, which comprises live attenuated M. bovis [61]) or killed bacteria (e.g., the first type of pertussis vaccine, which contains whole-cell killed Bordetella pertussis $[62,63]$ ) species. Bacteria have also been used in multiple forms as vaccine carriers to transmit distinct types of antigenic signals to activate the immune system against tumors [64].

\section{Bacteria-Based Microrobots (Bacteriobots): New Gadgets for Cancer Therapy}

For a long time, scientists have focused on researching and designing different types of biomedical microrobots as a practical means for drug delivery, microscopic surgery, and cancer treatment. Recently, bacteria-based microrobots have been posited as a viable alternative for cancer treatment. The concept of bacteriobots is an innovative and novel bacteria-based method for triggering antitumor actions [65]. Bacteriobots are bacteria-based devices with a similar structure that can be applied for targeting specific cells (i.e., for drug delivery or attacking them), and can be exploited in free or granulated form.

As described to before, to increase bacteriobots' efficiency, bacteria can be encapsulated/granulated in biodegradable and biocompatible microbeads, which are safe for human cells. The microbeads protect bacteria against opsonization and other physiological modifications which may occur in the body. These microbeads are in close contact with normal organs, and that is why it is vital to utilize appropriate microbeads to synthesize efficient bacterial robots for tumor targeting. The rate and mechanism of entrapped bacteria release from microbeads should be considered in the following steps of bacteriobots preparation. Ultimately, the bacterial flagella should be added to the microbial granules to facilitate the movement of bacterial robots and simplify the agents reaching the target tissue [66].

In one study, Salmonella typhimurium was adopted as part of a bacteria-based microbot. In this research, biocompatible alginate granules were used to encapsulate bacteria, and then $S$. typhimurium flagella were attached to the microbeads as a motility section. The experiments demonstrated that these robotic bacteria were able to target the tumor effectively [66].

In another study conducted by Al-Fandi et al., non-pathogenic $E$. coli were applied as live nanobots for cancer treatment. These live microrobots were equipped with naturally synthesized nano-biosensor systems bound to vascular endothelial growth factor (VEGF). The microbial nanobots were designed to detect and bind to tumor cells and the VEGF receptor was overexpressed in their membrane [67]. It is reported that robotic bacteria have greater chemotactic motility, more efficient cancerous tissue targeting, and higher migration rates to tumors compared to healthy cells. Moreover, this new generation of bacterial robots also acts as micro-stimuli and micro-sensors. This means that they can be applied as carriers for delivering therapeutic nanoparticles (NPs) and drugs to tumors. Therefore, bacteriobots may be a new 


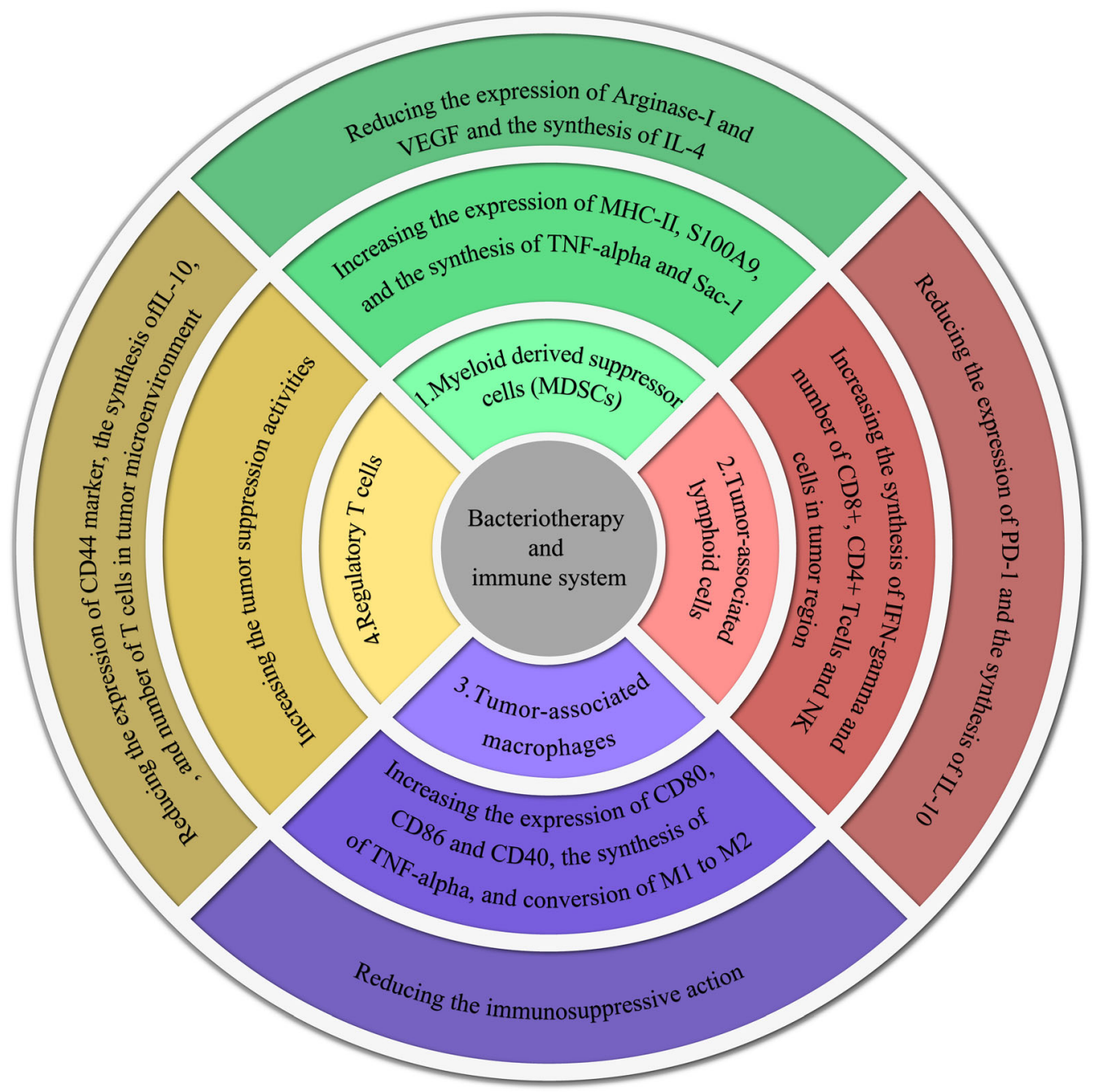

Fig. 4 The effect of bacteria on different antitumor immune cells: bacteria can be effective in cancer immunotherapy by accurately regulating the increasing-reducing responses against the tumor cells

therapeutic tool for detecting and fighting solid tumors [68]. In Fig. 5, the merits and benefits of utilizing bacteriobots, how they move to target tissues, and their effect on immune cells are illustrated.

\section{Most-Utilized Bacterial Species Applied for Cancer Treatment}

Many anaerobic bacteria studied so far can make spores under brutal conditions. These spores are highly resistant to unfavorable circumstances. They also permit bacteria to survive even in oxygen-rich environments, which are not desirable for anaerobic bacteria. These spores can get active and germinate to the living form of bacteria as soon as they find favorable conditions, such as hypoxic areas in the necrotic tissue within tumors. These features make spore-producing anaerobic bacteria an ideal choice for targeting cancer cells. Genetically modified strains of C. novyi-NT are free of lethal toxins and do not cause any systemic side effects on the injected host. Cell lysis in the tumor tissues was observed in mice with uterine cancer that had received $C$. histolyticum spores via intrauterine injection. The same result was recorded in mice that received $C$. sporogenes spores by intravenous (I.V.) injection [69]. 


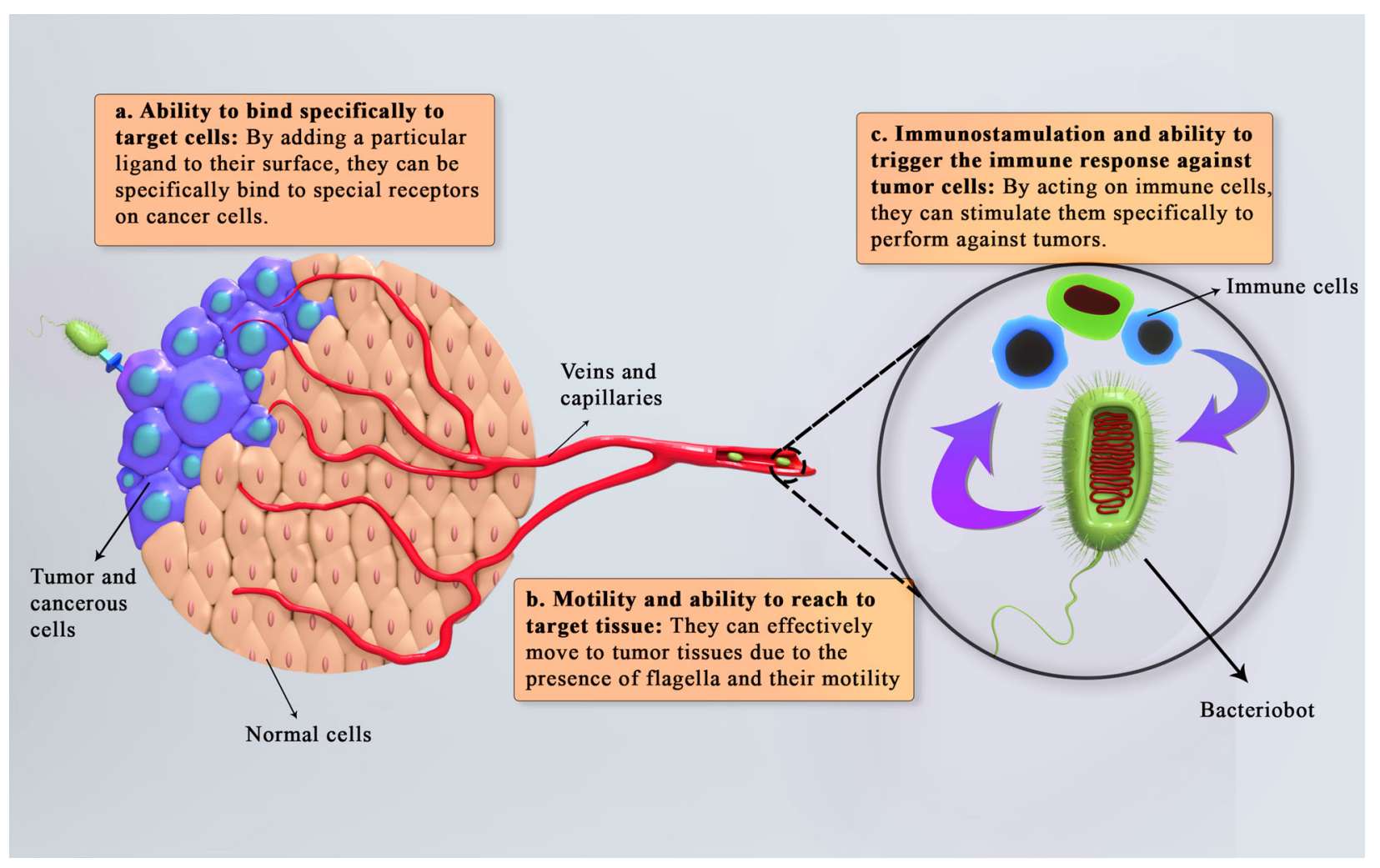

Fig. 5 Schematic in vivo image of bacteria applied for bacteriotherapy: specific binding of bacteria to tumor cells and nonbinding to normal cells (a). How bacteria move in capillaries and veins (b) and their effect on immune cells (c)

Pharmacological and toxicological evaluation of C. novyi-NT spores indicated that the reticuloendothelial system (RES) rapidly eliminates spores from the circulatory system. No clinically harmful toxins were found in the healthy mice or rabbits that received these spores, even at high doses [70]. Spores produced by bacteria have also been utilized as carriers for delivering anticancer compounds. Bacterial spores can also deliver various agents like cytotoxic peptides, therapeutic proteins, and genetic materials.

Some modifications in tumor cells following spore injection, such as mitochondrial failure, increased metabolism, cellular signaling, etc., increase the reactive oxygen species (ROS) concentration. An excessive increase in ROS in cancer cells can lead to tumor cell death [71]. Bacteria can be used to elevate the level of ROS in cancer cells and kill them. The application of bacteria as therapeutic agents against solid tumors also has been studied and tested. Facultative anaerobic bacteria seem to be able to invade and multiply in the hypoxic regions of solid tumors. As a result, they can slow down the growth rate of tumors or cause them to regress. However, a significant challenge for cancer bacteriotherapy using facultative aerobic-anaerobic bacteria is to prevent typical tissue damage. Consequently, the virulence of the bacteria has to be sufficiently reduced for medical utilizations [72].

As mentioned, the live, attenuated, killed, and genetically modified bacteria can be exploited as vectors to deliver conventional drugs, anti-angiogenic genes, and tumor-killing molecules. In the following section, the most important bacterial species used for therapeutic aims are discussed. 


\section{Salmonella typhimurium}

Extensive current research has shown that an altered strain of $S$. typhimurium can be applied to target tissues as a carrier for drug delivery. It can also be used as a gadget to make genomic alterations in genes that encode tumor-suppressing proteins through gene therapy. Scientists have designed genetically modified bacteria using $S$. typhimurium that were used for cancer therapy. Two genes (i.e., msbB and purI) were deleted entirely from the wild strain in the modified bacteria. This deletion was aimed at ultimately weakening these bacteria to prevent the occurrence of disease or toxic shock in the host or experimental animals. The purI gene deletion increases the bacteria's demand for external sources of adenine. The msbB gene was the second gene to be removed, aiming to decrease $S$. typhimurium toxicity by reducing nitric oxide and proinflammatory cytokine (such as TNF- $\alpha$ ) synthesis [73]. Deleting these two genes has effectively attenuated this bacterium by making it dependent on the exterior depots of purine nucleotides for endurance. On the one hand, this dependency prevents the microorganism from germinating and multiplying in the healthy tissues of the host body, such as the liver or spleen, but on the other hand, it enables it to grow in tumors in which purine nucleotides are abundant for bacteria. This bacterial vector displayed a long-term impact against many induced tumors and could kill metastatic cancer cells [74].

Such strains, which are biologically stable, demonstrated no resistance to antibiotics. Thus, they can be used to prevent cancer cell proliferation. A weakened form of S. typhimurium has favorably passed phase I clinical trials [75] and has been tested in other experiments [76]. The bacteria have also been utilized to deliver the genes that encode cytosine deaminase to E. coli. It has been observed that strains of $S$. typhimurium are significantly effective in collapsing tumor structures. Diverse cancer cell lines such as human pancreatic cancer (ASPC-1) and colon cancer cell lines (including C38, WiDr, and CT26) have been observed to be damaged by altered $S$. typhimurium [77]. In another study conducted by Daniel Saltzman [47], a recombinant attenuated $S$. typhimurium called Saltikva was used for cancer treatment. It is reported that Saltikva contains the human IL-2 gene, which causes robust antitumor responses by expressing this gene in the tumor microenvironment [47].

\section{Listeria monocytogenes}

Listeria monocytogenes synthesize listeriolysin $\mathrm{O}$ (LLO). LLO is one of the virulence factors of this bacterium that can cause bacterial survival by preventing phagolysosome formation in the host cells [78, 79]. LLO can also perforate the phagosome membrane to help bacteria escape from phagosomes and enter the intracellular space [79]. This type of bacteria has a broad domain of usages, such as serving as a carrier for vaccine delivery that induces antitumor responses by triggering the host immune system's cells [80, 81]. Various kinds of this antitumor vector are in phases I and II of clinical trials $[82,83]$. ADXS31-142 is a recombinant Lm-LLO invested in and developed by Advaxis Inc. against prostate cancer [83]. Listeria monocytogenes is also broadly used for cancer treatment against the Colo205 cell lines (human CRC cell line) [84].

\section{Bifidobacteria}

Bifidobacteria can target tumor cells by influencing the host immune responses and exert their anticancer effects by modifying the intestinal microbiota and synthesizing anticancer molecules [85]. Bifidobacterium adolescentis SPM0212 has demonstrated antitumor actions against Caco-2 and HT-29 cell lines by increasing TNF- $\alpha$ and nitric oxide synthesis. In contrast, B. longum SPM1205 is known for its TNF- $\alpha$ inhibition performance and its ability to interfere and disrupt toxic fecal enzymes such as $\alpha$-glucuronidase, tryptophanase, $\alpha$-glucosidase, and urease, which leads to an increment in the chance of gastrointestinal cancer incidence [86]. An in vivo study was conducted by Hyeyoon Kim et al. [87] about the effect of B. longum RAPO, as a member species, on the cancer treatment with anti-PD-1 (anti-death protein 1) antibody as an immune checkpoint inhibitor (ICI). This study's results indicated that the combination of immunotherapy with anti-PD-1 
agents and bacteriotherapy with $B$. longum RAPO, respectively, can modulate the antitumor immune responses and enhance the effect of anti-PD-1 in treating triple-negative breast cancer (TNBC) [87].

\section{Clostridium}

Spores of some Clostridium species, as anaerobic bacteria, are naturally absorbed into the hypoxic nuclei of tumors. They are able to target and partially lyse cancerous cells and tumors. As a consequence, the cancerous tissue is no longer able to resist conventional therapies, including chemotherapy. That is why these strains of Clostridium bacteria and their spores are indicated to be an appropriate option for combination treatments [88]. The antitumor effect of these bacteria can be increased by making modifications in genetically engineered strains, which cause the expression of prodrugconverting enzymes (PCE). It can also convert an inactive form of prodrugs to active and cytotoxic drugs at the tumor site $[89,90]$.

\section{Lactic Acid Bacteria}

Lactic acid bacteria (briefly identified as LABs) are beneficial microorganisms (also known as probiotics) that help improve the nutrition of foods, balance the microbial population of the gut microbiota, strengthen the immune and intestinal tract, and lower cholesterol ranges in the blood [91]. Although these bacteria are present in many foods, most experiments have been performed to study them in the laboratory and on dairy products [92].

\section{Weissella cibaria}

Weissella is a member of LABs isolated from the Lactobacillus family recently identified by DNA analysis techniques. This gram-positive microorganism, which lacks the catalase enzyme, is generally not pathogenic to the human body. Studies show that probiotic microorganisms, including LABs, can exert antitumor, anti-inflammatory, immune-modulating, and cholesterol-lowering functions by exopolysaccharides (EPS) [93].

\section{Escherichia coli Nissle}

Escherichia coli and other anaerobic bacteria can multiply in solid tumors and surround their microenvironment, often stopping tumor growth or even destroying and clearing them from the body. Escherichia coli Nissle 1917 may be used as a probiotic medicine or diagnostic agent and should be prescribed orally. This bacterium can help physicians distinguish liver metastasis by producing chemical signals that are easily detectable in the urine. These outcomes reveal that bacteriotherapy can be used for the treatment and diagnosis of cancer [92]. Another example of using Escherichia coli to affect tumor regression is a study conducted by Sreyan Chowdhury et al. [94]. In the mentioned study, Chowdhury et al. manipulated a nonpathogenic E. coli to be programmable lysed in the tumor microenvironment while releasing an encoded nanobody antagonist of CD47. Their experiment outcomes show a remarkable tumor regression, $\mathrm{T}$ cell activation, and metastasis prevention [95].

\section{Bacterial Virulence Factor as Anticancer Particles}

Virulence is defined as the ability of a microorganism, such as a bacterium, to cause disease and infection in the host. Virulence factors are cellular structures, chemical compounds, or biological molecules synthesized by that organism that help it bind to a niche, survive, replicate, eliminate competitors, or infect the host [96]. Pathogenic bacteria have various factors, including bacterial peptides, bacteriocin compounds, and enzymes or toxins. These compounds occasionally have antitumor properties and can be utilized for medical applications. Other cytotoxic compounds can be consumed to target tumor cells. These substances include phytochemical molecules [97], marine compounds (occasionally produced by marine bacteria), etc. Some marine and bacterial compounds can kill cancer cell lines by triggering specific signaling pathways such as mitogen-activated protein kinase (MAPK) [98]. 


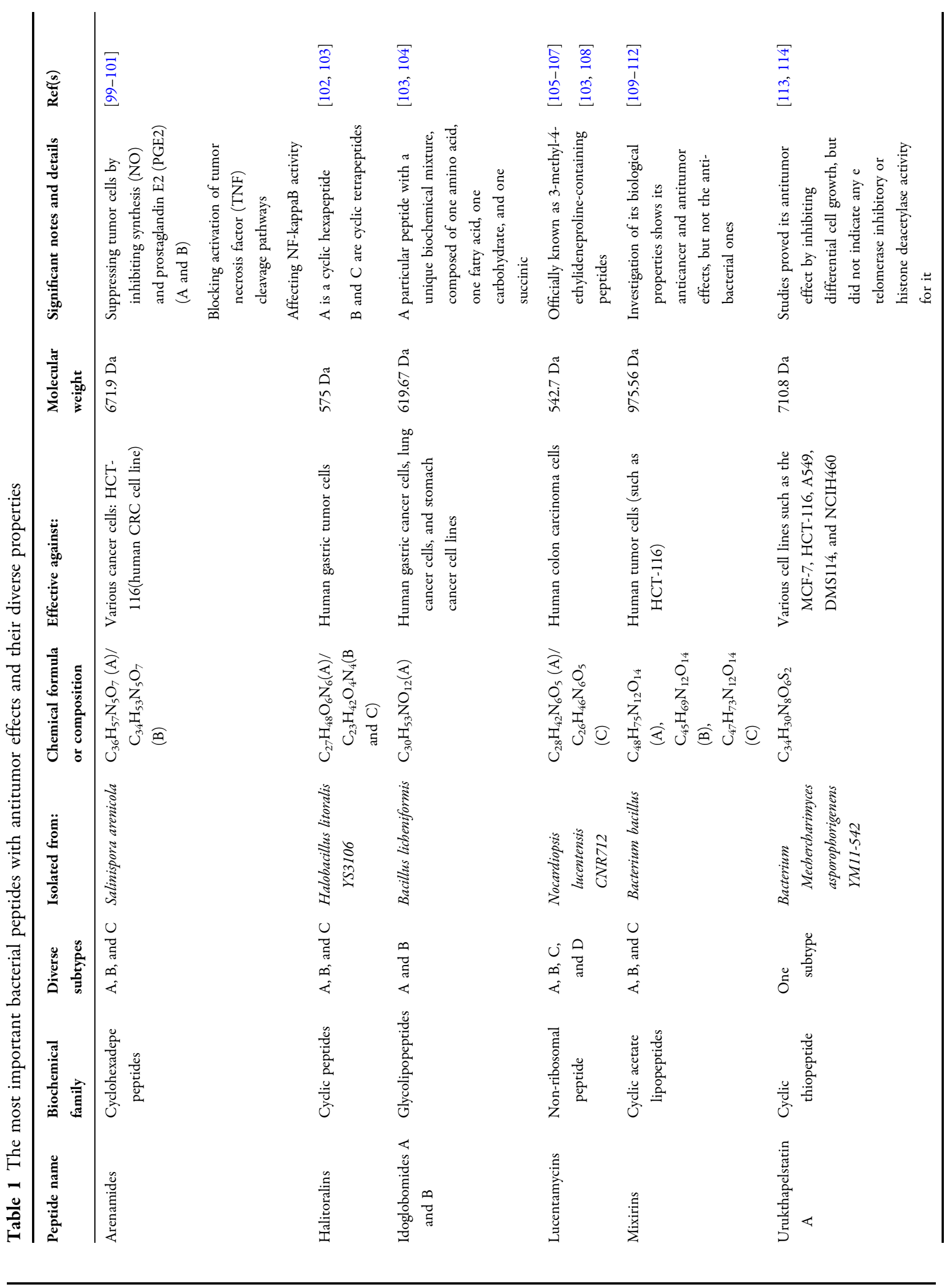




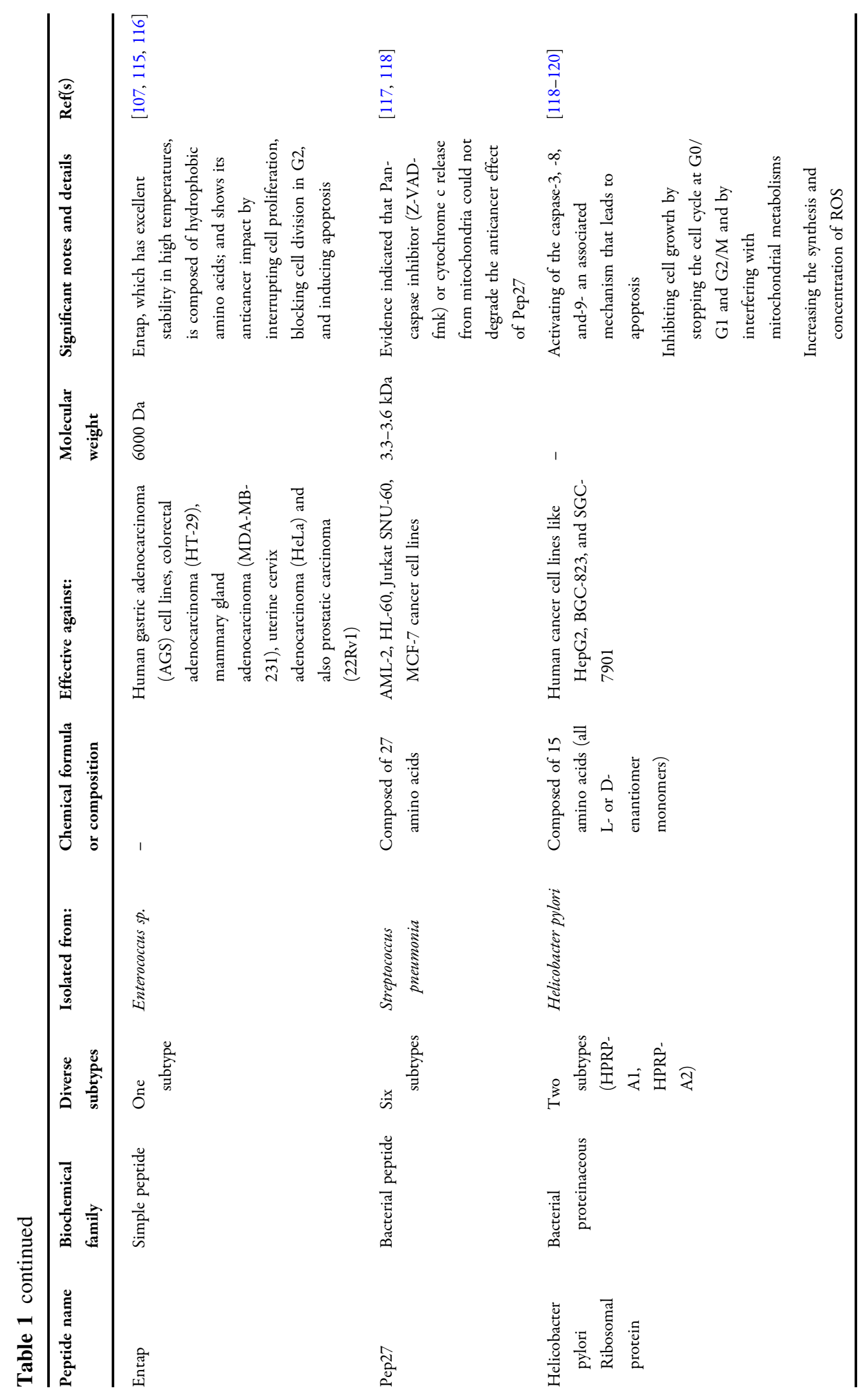




\section{Bacterial Peptides}

Bacterial peptides are substances released from bacteria and can have anticancer properties. Anti-bacterial and anticancer properties of diverse types of bacterial peptides are being studied and identified currently. The most wellknown and critical bacterial peptides with antitumor features include Arenamides, Halitoralins, Idoglobomides A and B, Lucentamycins, Mixirins, Urukthapelstatin, Entap, Pep27anal2, and Helicobacter pylori ribosomal protein. The most important data about these bacterial peptides and their anticancer properties are provided in Table 1.

\section{Bacteriocins}

Bacteriocins are known mainly as protein compounds synthesized by different bacteria to prevent other bacterial species' growth or even kill them. These bacterial products include microcins (which have $<20 \mathrm{kDa}$ weight), colicins (which weigh 20 to $90 \mathrm{kDa}$ ), and tacticians (which are heavier than others). Bacteriocins are divided into four groups. The first type of bacteriocin is called class I, also named lantibiotics. They have a molecular weight $<5 \mathrm{kDa}$ and contain unusual/abnormal amino acids in their structure. Specific instances of this group are nisin, lectin, and miracidian [121]. Class II bacteriocins are the second type of bacteriocins, including heat-resistant peptides with a weight $<10 \mathrm{kDa}$, divided into three subclasses IIa, IIb, and IIc [122]. Heat-sensitive peptides with a molecular weight $>30 \mathrm{kDa}$ are the third type of bacteriocins. It can disrupt cell membranes' function and structure and is partitioned into subclasses IIIa and IIIb. The fourth group includes proteins that are very high in lipids and carbohydrates [123]. Bovicin HC5, nisin A, pediocins, fermenticin HV6b, colicins, and S2 pyocin are crucial bacteriocins with antitumor properties that can be exploited in cancer therapy. The various characteristics of these bacteriocins have been studied from different perspectives and are summarized in Table 2.

\section{Bacterial Toxins}

Bacteria can synthesize toxins that can cause infections and disease by directly damaging host tissues and organs, weakening or disabling the immune system, or reducing a person's resistance to pathogens. By apoptosis induction and making modifications in the human cell division cycle and differentiation, these bacterial substances can disrupt the growth and expansion of host cells so that they can interpret cancerous cell mechanisms. Furthermore, various toxins (which are synthesized by bacteria) are able to act against various cancer cells in the human body, some of which are described below.

\section{Diphtheria Toxin}

Corynebacterium diphtheria produces a specific two-component toxin with a $60-\mathrm{kDa}$ molecular weight consisting of 538 amino acids known as diphtheria toxin (DT). DT-coding gene can be transmitted to $C$. diphtheria via Bacteriophage $\mathrm{B}$. DT contains two subunits, namely the (1) beta subunit, which can attach to the receptors of host cells and transmit the alpha subunit, and (2) alpha subunit, which interferes with the cellular function. Alpha subunits are responsible for ADP-ribosylation of cytoplasmic elongation factor 2 (EF-2), which ultimately causes the cessation of protein assembly and cell death [141]. Cross-reactive material 197 (CRM197) is an alerted and non-toxic type of DT that acts through various pathways such as inhibiting tumor metastasis and proliferation, reducing angiogenesis in the tumor site, inducing apoptosis, and acting as an immunological additive. Inhibition of heparin-binding epidermal growth factor has anticancer effects and exhibits antitumor properties. In addition, when CRM197 is used concomitantly with conventional chemotherapy drugs such as doxorubicin, this alerted form of DT reduces this drug's side effects and enhances its cytotoxic effect [142]. DTAT is another example of the other forms and molecules of DT toxin that have been chemically modified. This DT-based immunotoxin can target the tumor's vascular endothelium, causing cancerous tissue to regress and 
not grow in mice. DTAT is one of the modified forms of this DT toxin. Diphtheria toxin has shown toxicity against various human cancer cell lines as well as gastrointestinal cancer cells, including cortical adrenal carcinoma cell lines, colorectal cancer cell lines SW480, SW620, HCT116, CaCo-2, and HT-29 [143].

\section{Toxins of Clostridium difficile}

Clostridium difficile synthesizes distinct toxins, and two prominent ones are called cytotoxins (TcdB) and enterotoxins. (TcdA) [144]. TcdB demonstrates its anticancer activity by inducing the synthesis of proinflammatory chemokines and cytokines, inhibiting the reproduction of tumor cells, and inducting necrosis as well as apoptosis [144]. Furthermore, evidence from laboratory studies indicates that TcdB has remarkable immunogenicity features; it also promotes long-term antitumor immunity to various cancer cell lines and CT26 colon cancer cell lines and has the potential to be utilized as a vaccine to prevent or as antitumor drugs or immunotherapeutic agents to treat cancers and tumor cells [145].

\section{Verotoxin 1}

Verotoxin 1 (VT-1), mostly recognized as Shiga toxin-1 (Stx-1), is produced by members of the Enterobacteriaceae family, such as E. coli-which has VT and causes hemolytic uremic syndrome (HUS)_E. coli enterohemorrhagic (EHEC), and Shigella [146]. VT-1 inhibits protein synthesis and cell growth and interferes with the $S$ phase of the cell cycle. It has a membrane receptor called Globotriaosylceramide (Gb3), expressed in a broad range of MDR human cancer cell lines. VT-1 has shown antitumor activity and can stop the cell cycle in the HCT116 cell line of colon cancer [147].

\section{Exotoxin A}

This toxin is synthesized by Pseudomonas aeruginosa, having $66 \mathrm{kDa}$ molecular mass. Exotoxin $\mathrm{A}$ is a toxin that has an ADB-ribosylation function and inhibits protein elongation factor-2 (EF-2) activity. This toxin inhibits protein synthesis, causing apoptosis in the cancerous cells [148]. Exotoxin A, in its immunomodulatory phase, in combination with human epidermal growth factor (EGF) and interleukin-4 (IL-4), has demonstrated potent antitumor activity in PaCa- 2 cell lines of pancreatic cancer [149].

\section{Antitumor Enzymes with Bacterial Origin}

Arginine deiminase-I (ADI) is a bacterial enzyme with about $46 \mathrm{kDa}$ molecular weight synthesized by Mycoplasma hominis or M. arginine. Cutting and converting arginine to citrulline, which terminally results in ammonium release, is metabolized by this enzyme [149]. ADI-PEG20 is the name of arginine deaminase, which is conjugated to polyethylene glycol (PEG) polymers. It exerts its anticancer effect by inducing caspase-independent apoptosis, reducing tumor cells' physiological metabolism, inhibiting tumor cell growth and reproduction, and inducing autophagy [149]. It has led to the utilization of arginine deiminase as an anticancer agent, and its related clinical trials are in clinical phase II. This enzyme demonstrates excellent cancer treatment potential in different cancerous cell lines and liver carcinoma cell lines [150].

\section{Utilizing Bacteria for Cancer Therapy by Gene Delivery}

One of the significant challenges in utilizing bacteria as anticancer devices has been balancing the toxicity with the dose required for their effectiveness. These bacteria may be highly toxic to the host at high doses. On the other hand, a major barrier to gene therapy cancer treatment is specifically targeting solid tumors. One way to obviate these restrictions is to apply bacteria in a genetically modified manner to express specific proteins when used as the vectors for gene therapy [151]. As previously stated, the bacteria can contribute to the gene therapy process by carrying a specific gene and inducing a target protein synthesis in the cancer cells' environment. These bacterial carriers can be an effective and remedial adjuvant for a variety of cancer therapy methods. Chemotherapeutic compounds, cytotoxic peptides, remedial 
proteins, prodrug-to-drug-converting enzymes in solid tumors, and even coding and noncoding gene delivery can all be delivered using bacteria [152]. Various ways by which bacteria can directly or indirectly have an impact on and kill tumor tissues and cancerous cells are illustrated in Fig. 6.

\section{Available Clinical Data and Trials on the Efficacy of Bacteria-Based Methods for Cancer Therapy}

Although promising outcomes in various situations have accompanied the utilization of bacteria-based methods, unfortunately, these innovative therapies have not been used widely in the clinical oncology [42]. As Shiyu Song et al. [42] stated, while the high potential of bacteria-based methods for solid tumors has been known in the last decades, the principal possible reason for not using bacteria, these "double-edged swords," may be their adverse and unmanageable side effects. As mentioned before, the BCG vaccine-which is the attenuated form of M. bovis-is the only bacteria-based agent authorized by the US Food and Drug Administration (US-FDA) and is widely employed as the standard of care for the treatment of patients suffering from the NMIBC $[153,154]$. However, the available clinical data have demonstrated that BCG vaccine treatment in $30-50 \%$ of the NMIBC patients fails to result in discernable and positive outcomes [155]. Moreover, $5 \%$ of the NMIBC patients who received BCG encountered adverse effects such as tissue sepsis and infections [155].

While available clinical data on bacteriotherapy seem to be limited, recently, there has been great enthusiasm in the scientific community resulting in various pre-clinical and clinical trials on bacteria-based methods. For example, intratumoral administration of $C$. novyi spores has been utilized to treat one patient suffering from advanced leiomyosarcoma, and the results were remarkably efficient [7]. Furthermore, the usage of attenuated $L$. monocytogenes species for treating patients with advanced cancer has been reported to be safe and effective $[156,157]$. A phase I clinical trial reported by Wood et al. [158] on the expression of HPV16 E7 (as an oncoprotein) by attenuated L. monocytogenes has shown a $30 \%$ tumor reduction in overall survival. There were also some common side effects, such as flu-like symptoms, in the patients [158]. As described above, there were also some pre-clinical studies on bacteria-based methods. A pre-clinical study $[159,160]$ on commensal Bifidobacterium was conducted to evaluate the efficacy of selectively expressed CD in hypoxic mammary cancerous tissue in rats and converting the rate of 5-FC into 5 -FU $[161,162]$. In the following section, recent clinical trials on bacteria-based methods and their outcomes in the last 10 years are briefly discussed in Table 3 .

\section{Bacteriaotherapy: Risks and Challenges}

While radiotherapy and chemotherapy are well known as the foundations of cancer treatment, their outcomes are associated with some ups and downs in cancer patients [163]. As a result of previous inadequate and restricted anticancer therapies, mediated cancer treatment has drawn scientists' attention. Bacteriaotherapy for cancer treatment can be considered a novel treatment strategy with fewer side effects if applied correctly and can be utilized alone or as a booster with typical therapeutic methods. Bacteriotherapy, like other therapeutic approaches, has several advantages and disadvantages. One important point related to cancer therapy utilizing bacteria is that bacteria's pathogenicity leads to infection or even death in patients. Many studies have exploited weakened, alerted, or genetically manipulated species to eliminate these restrictions. Another downside of bacteriotherapy is the short half-life of bacterial peptides and proteins and unstable-mutatable DNA [164]. Various investigations have proved that using genetic engineering techniques to improve bactericidal agents' effectiveness by research can enhance antitumor effects of the bacteriotherapy method. For example, in some research, scientists have consumed biochemical changes and reactions such as D-amino acid replacement, 


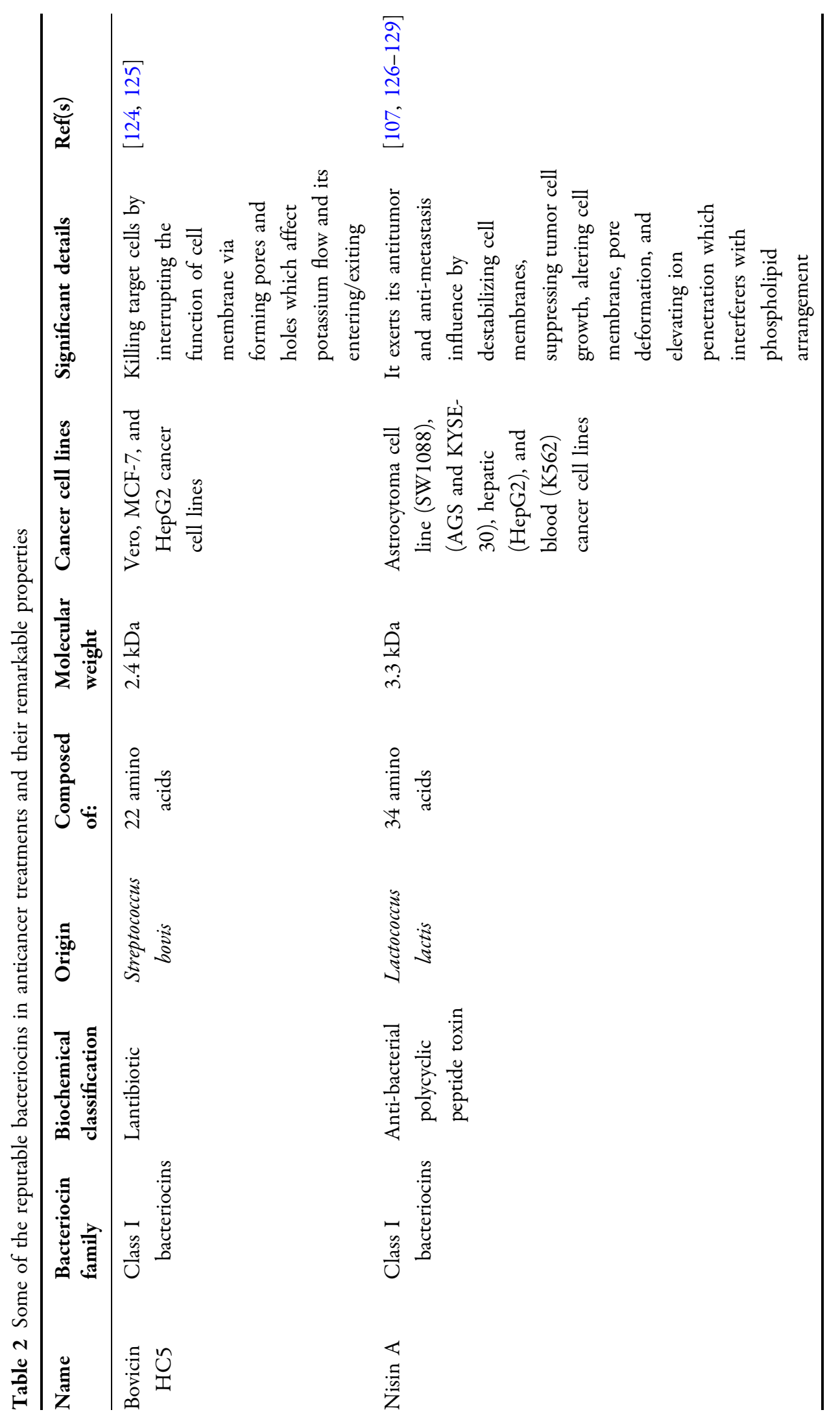




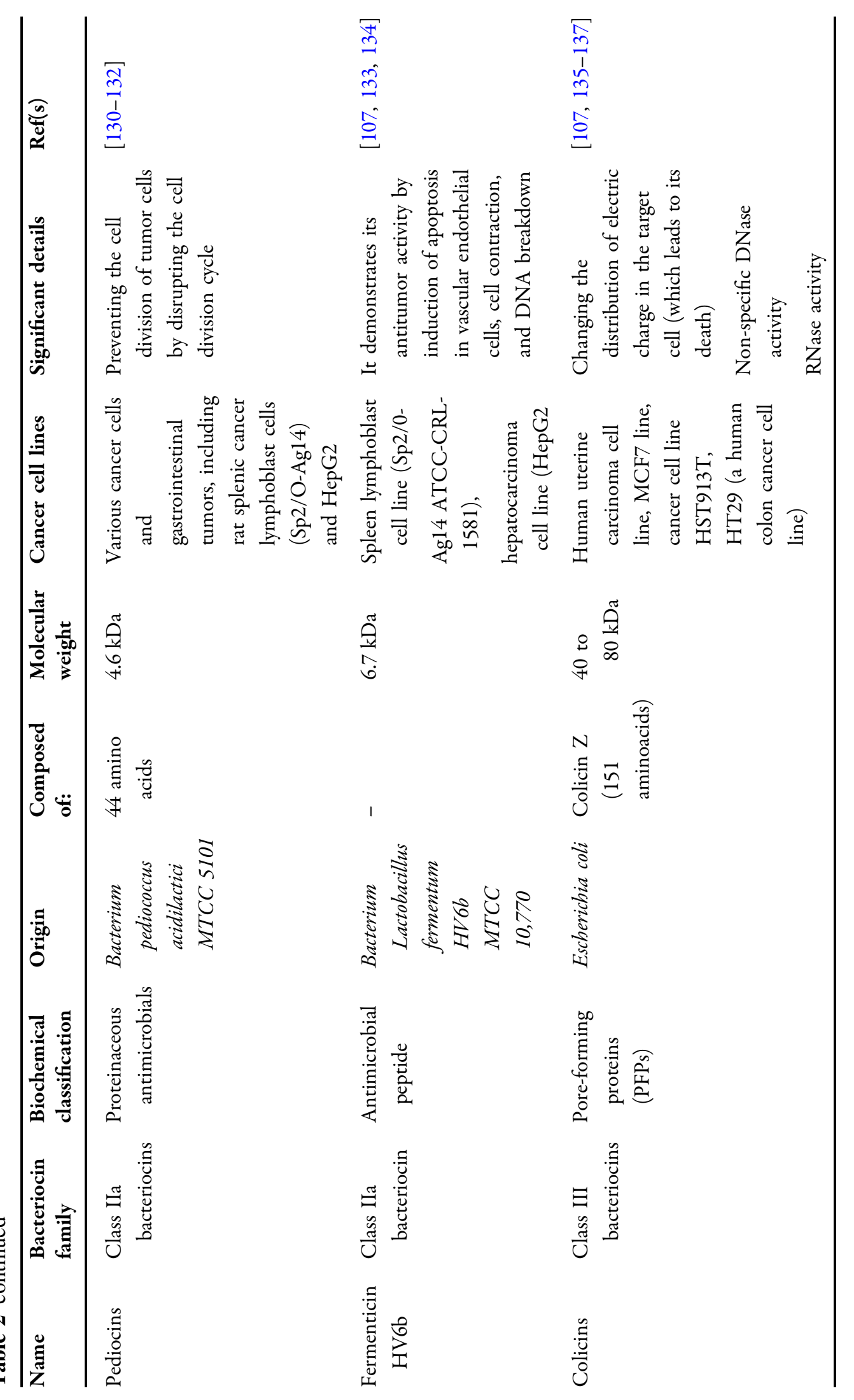




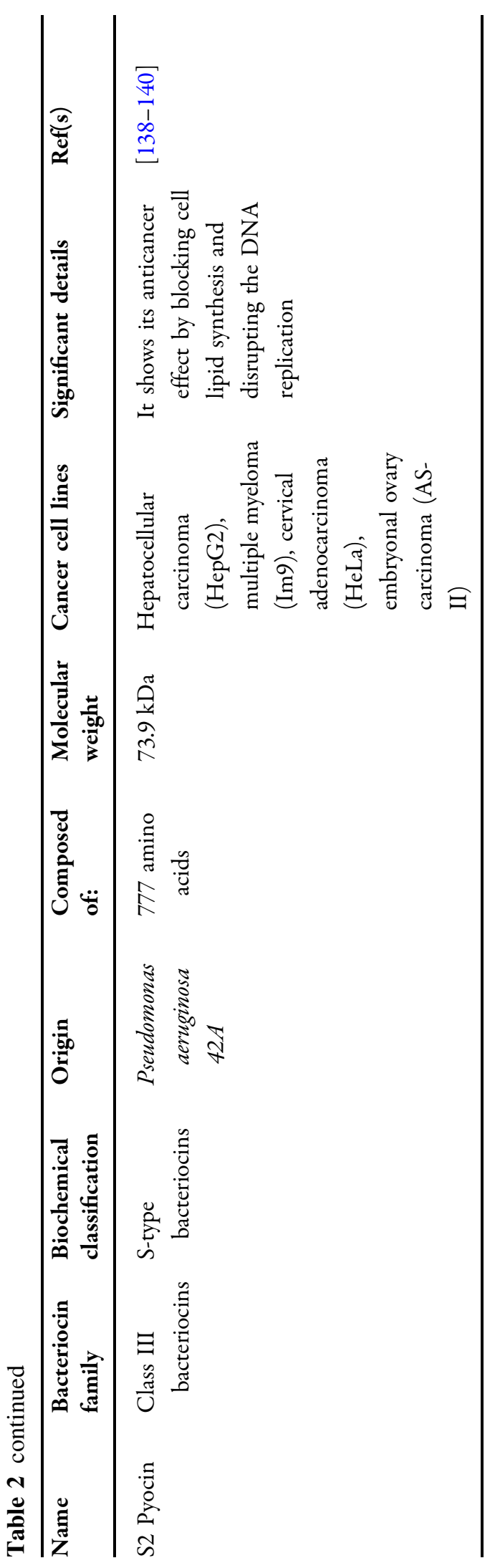

unstable amino acid replacement, etc., to increase the bactericidal agent's shelf-life and stability [165].

As mentioned, a tremendous obstacle to applying bacteria-derived medications as anticancer compounds is their low cytotoxicity at the dose required for therapeutic efficacy. Furthermore, systemic bacterial infections can be a significant risk factor for living organisms. Besides, even deletion of genes encoding the toxin and virulence factors could result in the death of about $15-45 \%$ in test mice [166]. Another significant challenge to applying bacteria for cancer treatment is incomplete tumor lysis. The bacteria do not lyse any part of the cancerous tissue and may not effectively eradicate it. Therefore, the administration of concomitant therapies such as chemotherapy plus bacteriotherapy is essential to achieve the desired outcomes. A more difficult obstacle with bacteriotherapy is that it is challenging to treat small non-necrotic tumors from the metastasis of large tumors (the leading cause of cancer death) with this method. Due to the physiological problems and communication knots with hypoxia in these cancerous tissues, it is difficult for bacteria to target these issues accurately. In bacterial therapy based on live bacteria, the main problem is the lack of accurate access of these bacteria to tumors since, in most cases, an intra-tumor infusion is required [167]. Another primary risk of bacterial immunotherapy is the chance for modifications in nucleic acids and DNA mutations. Suppose the host body's bacterial DNA has a mutation or its genetic material changes through nucleic acid modification. This can lead to the bacterium losing its original anticancer function because of the conversion. It can prelude various problems such as failure to treat tumors or severe bacterial infections in the host organs. Although some concerns about treating cancer with bacterial therapy have been addressed using recombinant DNA technology, more research, studies, and experiments are warranted [168]. A summary of the pros and cons of applying bacteriotherapy for treating cancer is given in Fig. 7. 


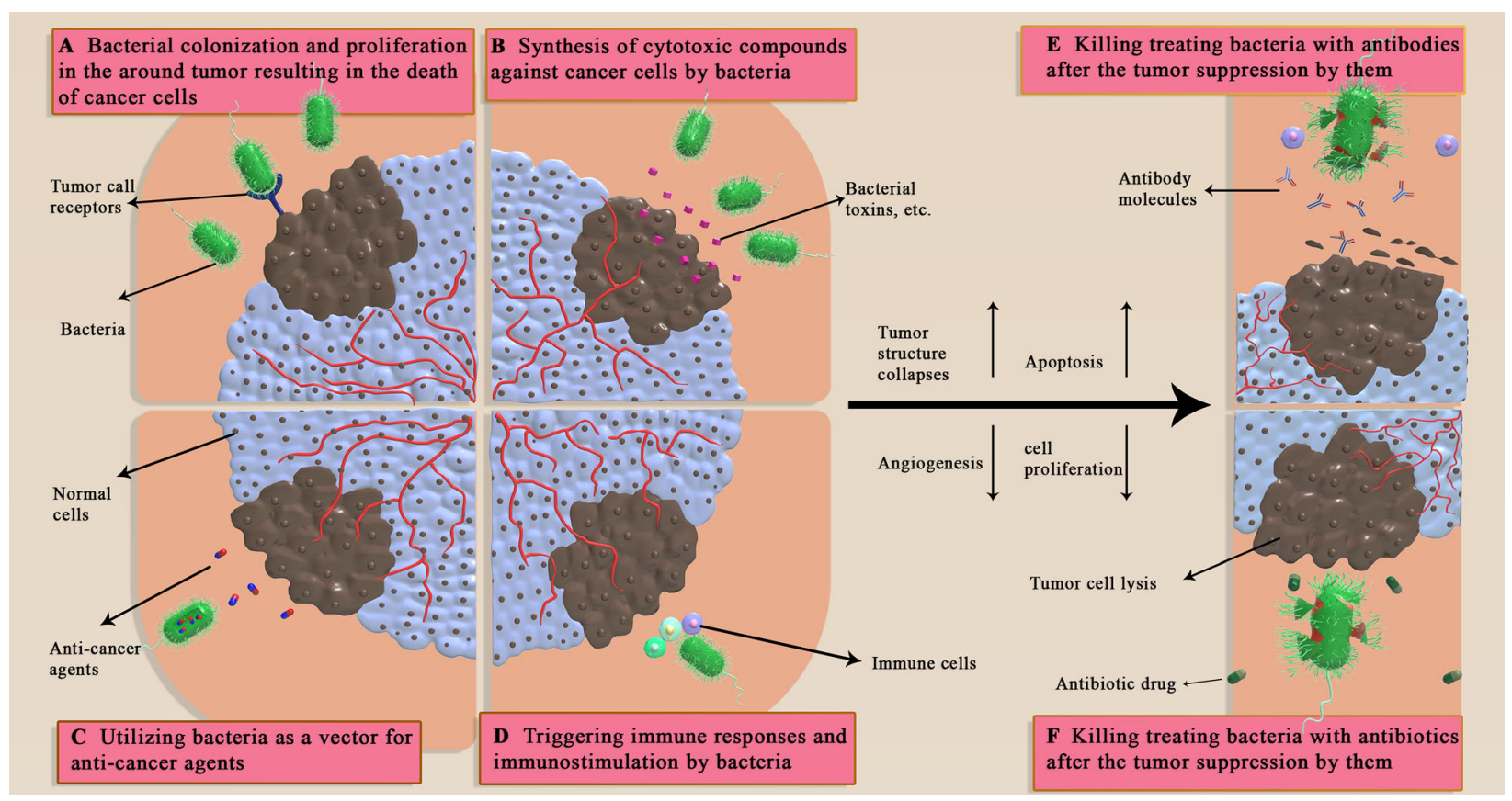

Fig. 6 Bacteria or their chemical derivations can have anticancer effects. Colonized bacteria consume available oxygen and nutrients and may result in the cancerous cells' death (A). Bacteria can also synthesize various chemical compounds that may have antitumor effects $(\mathbf{B})$; they have the potential to be used as a carrier for anticancer agents

\section{CONCLUSION}

Bacteriotherapy has been posited and considered to be one of the most advanced methods that can be used for cancer therapy. The ability to replicate in the body and having no requirement for repetitive injections as well as specificity in exerting cytotoxic impacts on cancer cells, and the possibility of genetic modification to eliminate virulence factors, etc., are among the crucial attributes of bacteria that make them an appropriate candidate for cancer treatment. Like any other method, bacteriotherapy faces some challenges and risks. The possibility of pathogenicity of bacteria against healthy cells, their potential to have excessive and uncontrollable growth, their inability to lyse necrotic cells completely, and the lack of symmetrical growth in all tumor tissues are some of these challenges. Despite in vitro and
(C). Stimulation of the immune system by bacteria can result in immunotherapeutic effects (D). After killing tumor cells, used bacteria can be eliminated to prevent unintended bacterial infections. Bacteria are mainly cleared by antibiotics $(\mathbf{E})$ and immune cells $(\mathbf{F})$

in vivo studies, this method is still not widely utilized clinically, and its application against tumors has been associated with some concerns.

Thus, further investigations are essential to increase our knowledge in this area and to determine the advantages and disadvantages of bacteriotherapy. Moreover, reviewing all the research achievements can help scientists reach a consensus and make this method more efficient in future applications. Further investigations are essential to increase knowledge in this area and determine the advantages and disadvantages of bacteria-based strategies for cancer treatment. 


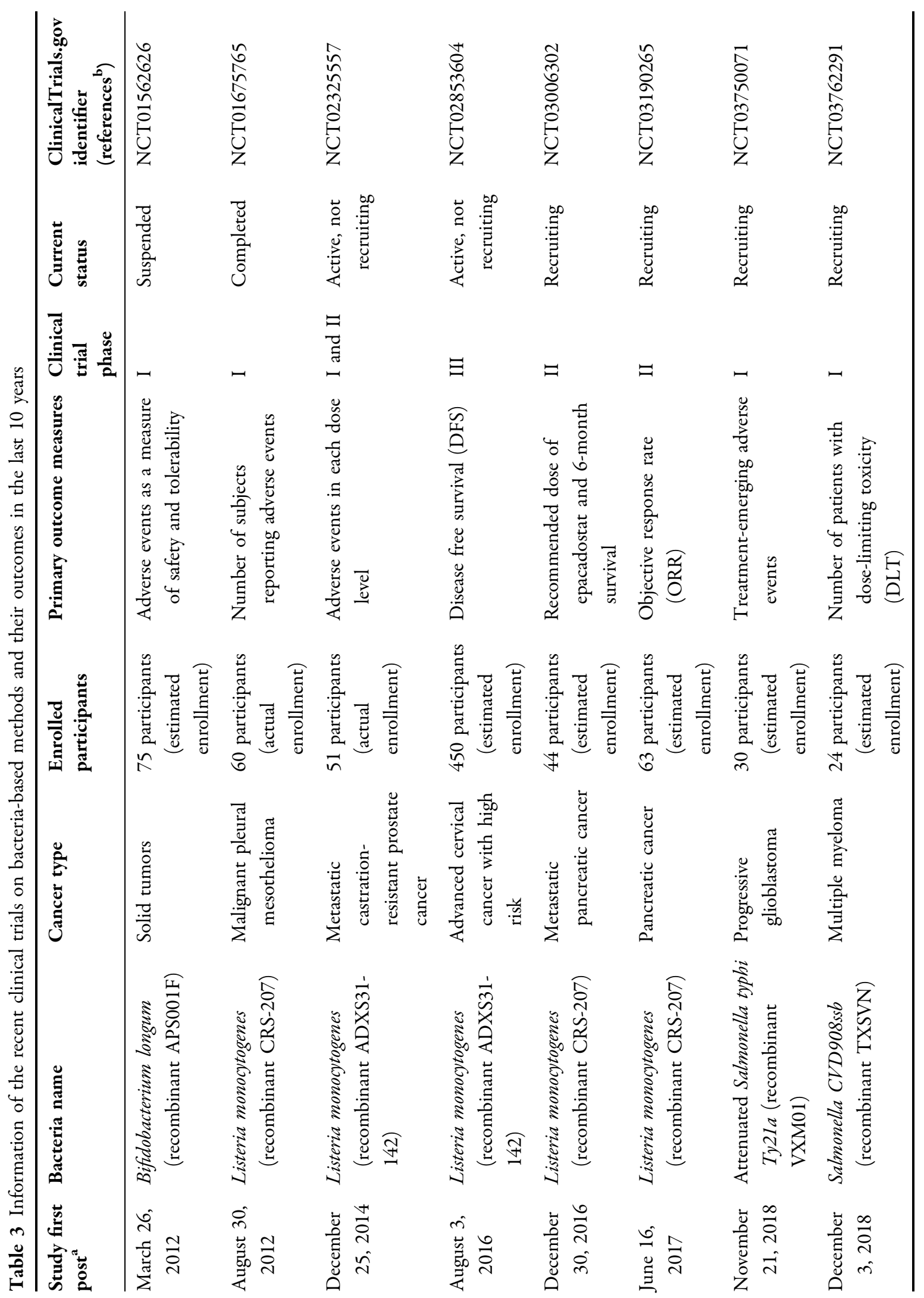




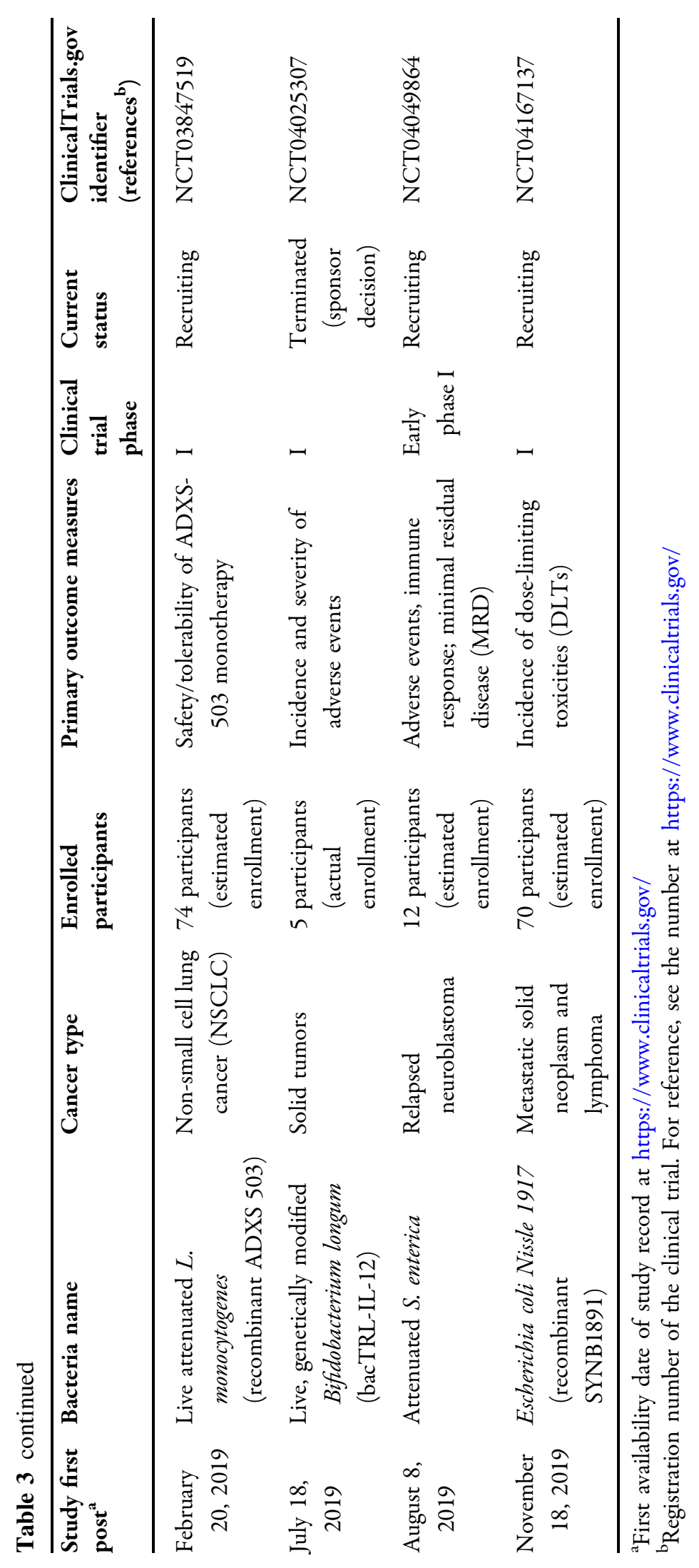




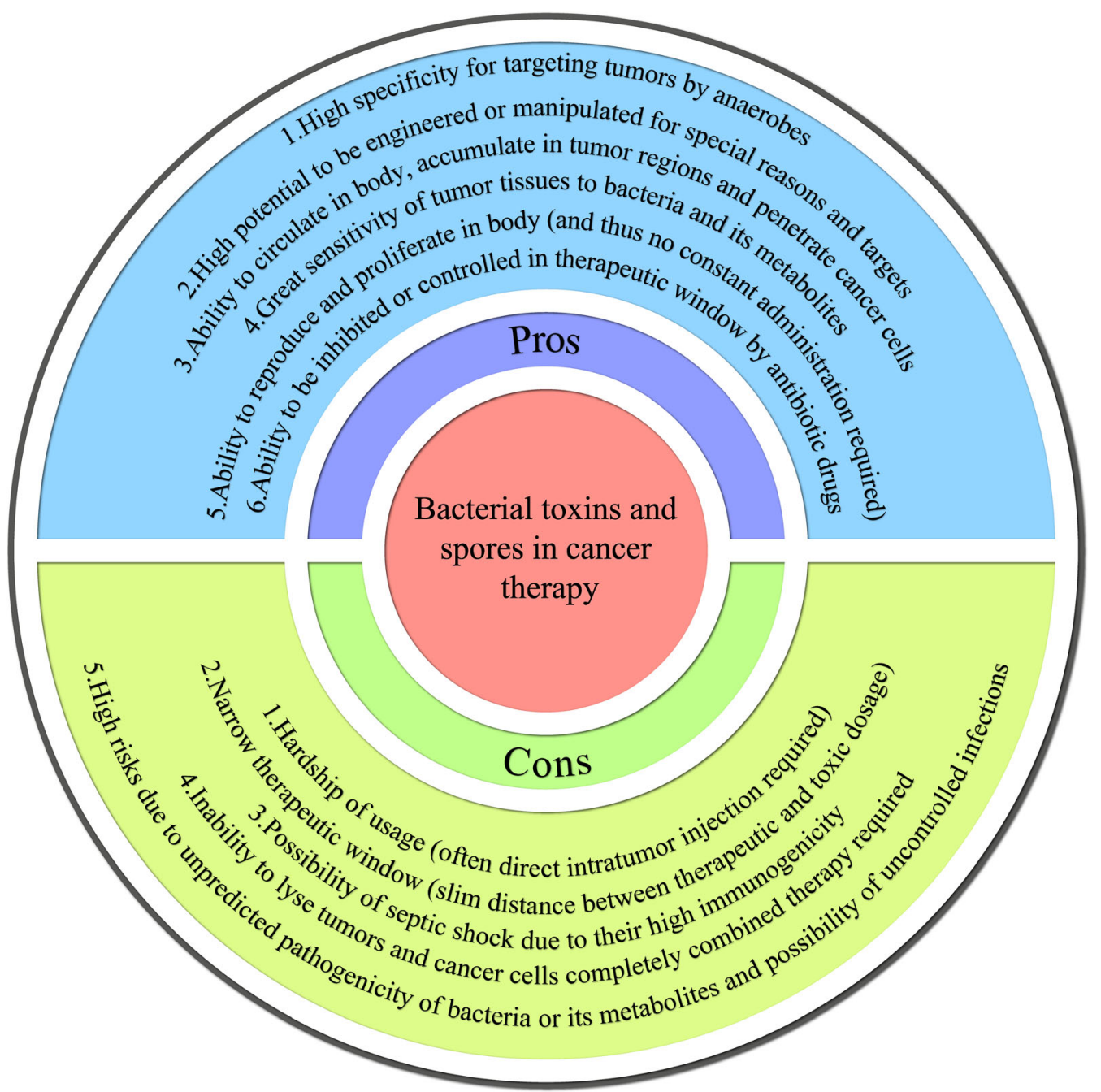

Fig. 7 Opportunities and challenges of bacteriotherapy for cancer treatment: the utilization of bacteria for cancer therapy should be comprehensively viewed, and its advantages and disadvantages must be considered

\section{ACKNOWLEDGEMENTS}

The author sincerely thanks Dr. Neda Soleimani because of her support and consultations.

Funding. No funding or sponsorship was received for this study or publication of this article.

Authorship. The named author meets the International Committee of Medical Journal Editors (ICMJE) criteria for authorship for this article, takes responsibility for the integrity of the work as a whole, and has given their approval for this version to be published.

Author Contributions. The only author of this article is Foad Rommasi. All contributions, including conceptualization, investigation, writing-original draft preparation, writing-review, editing, and figures preparation, were performed by Foad Rommasi. The author has read the final manuscript intently and approved the published version of the manuscript. The author prepared all figures for this particular article, so there was no need for copyright permission. 
Disclosures. The only author of this article, by considering the International Committee of Medical Journal Editors (ICMJE) criteria and Committee on Publication Ethics (COPE), is Foad Rommasi. The author declares that he has no conflicts of interest.

Compliance with Ethics Guidelines. This article is based on previously conducted studies and does not contain any new studies with human participants or animals performed by any of the authors.

Data Availability. Data sharing is not applicable for this article, as no datasets were generated or analyzed during the current study.

Open Access. This article is licensed under a Creative Commons Attribution-NonCommercial 4.0 International License, which permits any non-commercial use, sharing, adaptation, distribution and reproduction in any medium or format, as long as you give appropriate credit to the original author(s) and the source, provide a link to the Creative Commons licence, and indicate if changes were made. The images or other third party material in this article are included in the article's Creative Commons licence, unless indicated otherwise in a credit line to the material. If material is not included in the article's Creative Commons licence and your intended use is not permitted by statutory regulation or exceeds the permitted use, you will need to obtain permission directly from the copyright holder. To view a copy of this licence, visit http://creativecommons.org/licenses/bync/4.0/.

\section{REFERENCES}

1. Organization WH. Global health estimates 2020: deaths by cause, age, sex, by country and by region, 2000-2019. Geneva: World Health Organization; 2020.

2. Baba AI, Câtoi C. Tumor cell morphology. In: Comparative oncology. Bucharest: The Publishing House of the Romanian Academy; 2007.
3. Jain R. New approaches for the treatment of cancer. Adv Drug Deliv Rev. 2001;46:149-68.

4. Pucci C, Martinelli C, Ciofani G. Innovative approaches for cancer treatment: current perspectives and new challenges. Ecancermedicalscience. 2019;13:961. https://doi.org/10.3332/ecancer.2019. 961.

5. Cassileth BR, Deng G. Complementary and alternative therapies for cancer. Oncologist. 2004;9(1): 80-9.

6. Miller KD, Siegel RL, Lin CC, Mariotto AB, Kramer $\mathrm{JL}$, Rowland $\mathrm{JH}$, et al. Cancer treatment and survivorship statistics, 2016. CA: Cancer J Clin. 2016;66:271-89.

7. Roberts NJ, Zhang L, Janku F, Collins A, Bai R-Y, Staedtke $\mathrm{V}$, et al. Intratumoral injection of Clostridium novyi-NT spores induces antitumor responses. Sci Transl Med. 2014;6:249ra111249 ra111.

8. Malmgren RA, Flanigan CC. Localization of the vegetative form of Clostridium tetani in mouse tumors following intravenous spore administration. Can Res. 1955;15:473-8.

9. Lantier L, Poupée-Beaugé A, Di Tommaso A, Ducournau C, Germon S, Lee GS, et al. (2021) Neospora caninum: an immunotherapeutic protozoan against cancer. AACR. 81(13 Supplement). https://doi.org/10.1158/1538-7445.AM2021-1712.

10. Janku F, Zhang HH, Pezeshki A, Goel S, Murthy R, Wang-Gillam A, et al. Intratumoral injection of clostridium novyi-nt spores in patients with treatment-refractory advanced solid tumors. Clin Cancer Res. 2020;27:96-106.

11. Oelschlaeger TA. Bacteria as tumor therapeutics? Bioengineered bugs. 2010;1:146-7.

12. Busch W. Aus der Sitzung der medicinischen section vom 13 November 1867. Berl Klin Wochenschr. 1868;5:137.

13. Fehleisen F. Ueber die züchtung der erysipelkokken auf künstlichem nährboden und ihre übertragbarkeit auf den menschen. Dtsch Med Wochenschr. 1882;8:553-4.

14. Coley W. Disappearance of a recurrent carcinoma after injections of mixed toxins. Ann Surg. 1912;55: 897-8.

15. Flynn JL, Chan J. Immunology of tuberculosis. Annu Rev Immunol. 2001;19:93-129.

16. Daniel TM, Bates JH, Downes KA. History of tuberculosis. In: Tuberculosis: pathogenesis, protection, 
and control. Washington, DC: ASM Press; 1994. p. 13-24. https://doi.org/10.1128/9781555818357. ch2.

17. mondiale de la Santé O, Organization WH. Organization WH BCG vaccines: WHO position paper-February 2018-Vaccins BCG: note de synthèse de l'OMS-Février 20188. Weekly Epidemiol Record=Relev Épidémiol Hebd. 2018;93:73-96.

18. Simona L, Mihaescu T. History of BCG vaccine. Maedica. 2013;8:53.

19. Venkataswamy MM, Goldberg MF, Baena A, Chan J, Jacobs WR Jr, Porcelli SA. In vitro culture medium influences the vaccine efficacy of Mycobacterium bovis BCG. Vaccine. 2012;30:1038-49.

20. Tanghe A, Content J, Van Vooren J-P, Portaels F, Huygen K. Protective efficacy of a DNA vaccine encoding antigen 85A from Mycobacterium bovis BCG against Buruli ulcer. Infect Immun. 2001;69: 5403-11.

21. Rentsch CA, Birkhäuser FD, Biot C, Gsponer JR, Bisiaux A, Wetterauer C, et al. Bacillus CalmetteGuérin strain differences have an impact on clinical outcome in bladder cancer immunotherapy. Eur Urol. 2014;66:677-88.

22. Gontero P, Bohle A, Malmstrom P-U, O'Donnell MA, Oderda M, Sylvester R, et al. The role of bacillus Calmette-Guérin in the treatment of non-muscleinvasive bladder cancer. Eur Urol. 2010;57:410-29.

23. Alhunaidi O, Zlotta AR. The use of intravesical BCG in urothelial carcinoma of the bladder. Ecancermedicalscience. 2019;13:905.

24. Han J, Gu X, Li Y, Wu Q. Mechanisms of BCG in the treatment of bladder cancer-current understanding and the prospect. Biomed Pharmacother. 2020;129: 110393.

25. Yu D-S, Wu C-L, Ping S-Y, Keng C, Shen K-H. Bacille Calmette-Guerin can induce cellular apoptosis of urothelial cancer directly through toll-like receptor 7 activation. Kaohsiung J Med Sci. 2015;31:391-7.

26. Moriwaki Y, Begum NA, Kobayashi M, Matsumoto M, Toyoshima K, Seya T. Mycobacterium bovis Bacillus Calmette-Guerin and its cell wall complex induce a novel lysosomal membrane protein, SIMPLE, that bridges the missing link between lipopolysaccharide and p53-inducible gene, LITAF (PIG7), and estrogen-inducible gene, EET-1. J Biol Chem. 2001;276:23065-76.

27. Wells CA, Ravasi T, Faulkner GJ, Carninci P, Okazaki Y, Hayashizaki Y, et al. Genetic control of the innate immune response. BMC Immunol. 2003;4: $1-18$.
28. Olbert PJ, Kesch C, Henrici M, Subtil FS, Honacker A, Hegele A, et al. TLR4-and TLR9-dependent effects on cytokines, cell viability, and invasion in human bladder cancer cells. In: Urologic oncology: seminars and original investigations. Amsterdam: Elsevier; 2015. p. 110-e19-e27.

29. Zhang G-J, Crist SA, Mckerrow AK, Xu Y, Ladehoff DC, See WA. Autocrine IL-6 production by human transitional carcinoma cells upregulates expression of the $\alpha 5 \beta 1$ fibronectin receptor. J Urology. 2000;163:1553-9.

30. Brandau S, Suttmann H. Thirty years of BCG immunotherapy for non-muscle invasive bladder cancer: a success story with room for improvement. Biomed Pharmacother. 2007;61:299-305.

31. Ajili F, Kaabi B, Darouiche A, Tounsi H, Kourda N, Chebil $\mathrm{M}$, et al. Prognostic value of Bcl-2 and Bax tumor cell expression in patients with non muscleinvasive bladder cancer receiving bacillus CalmetteGuerin immunotherapy. Ultrastruct Pathol. 2012;36:31-9.

32. Bermudes D, Zheng L, King IC. Live bacteria as anticancer agents and tumor-selective protein delivery vectors. Curr Opin Drug Discov Devel. 2002;5:194-9.

33. Deng W, Lira V, Hudson TE, Lemmens EE, Hanson WG, Flores R, et al. Recombinant Listeria promotes tumor rejection by CD8+ T cell-dependent remodeling of the tumor microenvironment. Proc Natl Acad Sci. 2018;115:8179-84.

34. Galmbacher K, Heisig M, Hotz C, Wischhusen J, Galmiche A, Bergmann B, et al. Shigella mediated depletion of macrophages in a murine breast cancer model is associated with tumor regression. PLoS ONE. 2010;5:e9572.

35. Rodrigues AL, Trachtmann N, Becker J, Lohanatha $\mathrm{AF}$, Blotenberg J, Bolten CJ, et al. Systems metabolic engineering of Escherichia coli for production of the antitumor drugs violacein and deoxyviolacein. Metab Eng. 2013;20:29-41.

36. Touati E. When bacteria become mutagenic and carcinogenic: lessons from H. pylori. Mutat Res/ Genet Toxicol Environ Mutagen. 2010;703:66-70.

37. Gajewski TF, Schreiber $\mathrm{H}, \mathrm{Fu} \mathrm{Y}-\mathrm{X}$. Innate and adaptive immune cells in the tumor microenvironment. Nat Immunol. 2013;14:1014-22.

38. Raskov H, Orhan A, Christensen JP, Gögenur I. Cytotoxic CD8+ $\mathrm{T}$ cells in cancer and cancer immunotherapy. Br J Cancer. 2021;124:359-67.

39. Stern C, Kasnitz N, Kocijancic D, Trittel S, Riese P, Guzman CA, et al. Induction of CD $4+$ and CD $8+$ 
antitumor effector $\mathrm{T}$ cell responses by bacteria mediated tumor therapy. Int J Cancer. 2015;137: 2019-28.

40. Davar D, Dzutsev A, McCulloch JA, Rodrigues RR, Chauvin J-M, Morrison RM, et al. (2021) Abstract LB062: efficacy of responder-derived fecal microbiota transplant (R-FMT) and pembrolizumab in anti-PD-1 refractory patients with advanced melanoma. AACR. 81(Issue 13). https://doi.org/10.1158/ 1538-7445.AM2021-LB062.

41. Ganai S, Arenas RB, Sauer JP, Bentley B, Forbes NS. In tumors Salmonella migrate away from vasculature toward the transition zone and induce apoptosis. Cancer Gene Ther. 2011;18:457-66.

42. Song S, Vuai MS, Zhong M. The role of bacteria in cancer therapy-enemies in the past, but allies at present. Infect Agents cancer. 2018;13:1-7.

43. Nallar SC, Xu D-Q, Kalvakolanu DV. Bacteria and genetically modified bacteria as cancer therapeutics: current advances and challenges. Cytokine. 2017;89:160-72.

44. Heimann DM, Rosenberg SA. Continuous intravenous administration of live genetically modified salmonella typhimurium in patients with metastatic melanoma. J Immunother. 2003;26:179-80.

45. Sedighi M, Zahedi Bialvaei A, Hamblin MR, Ohadi E, Asadi A, Halajzadeh M, et al. Therapeutic bacteria to combat cancer; current advances, challenges, and opportunities. Cancer Med. 2019;8:3167-81.

46. Baindara P, Mandal SM. Bacteria and bacterial anticancer agents as a promising alternative for cancer therapeutics. Biochimie. 2020;177:164-89. https://doi.org/10.1016/j.biochi.2020.07.020.

47. Saltzman D (2021) Abstract LB161: microbial based immunotherapy: saltikva as a novel therapeutic for solid tumors. AACR. 81(13 Supplement). https:// doi.org/10.1158/1538-7445.AM2021-LB161.

48. Kerkar SP, Restifo NP. Cellular constituents of immune escape within the tumor microenvironment. Can Res. 2012;72:3125-30.

49. Galdiero MR, Bonavita E, Barajon I, Garlanda C, Mantovani A, Jaillon S. Tumor associated macrophages and neutrophils in cancer. Immunobiology. 2013;218:1402-10.

50. Rodriguez PC, Quiceno DG, Zabaleta J, Ortiz B, Zea $\mathrm{AH}$, Piazuelo MB, et al. Arginase I production in the tumor microenvironment by mature myeloid cells inhibits T-cell receptor expression and antigenspecific T-cell responses. Can Res. 2004;64:5839-49.
51. Fabian MR, Sonenberg N. The mechanics of miRNAmediated gene silencing: a look under the hood of miRISC. Nat Struct Mol Biol. 2012;19:586.

52. Martinez F, Sica A, Mantovani A, Locati M. Macrophage activation and polarization. Front Biosci. 2008;13:453-61.

53. Bourke JM, O'Sullivan M, Khattak MA. Management of adverse events related to new cancer immunotherapy (immune checkpoint inhibitors). Med J Aust. 2016;205:418-24.

54. Byun DJ, Wolchok JD, Rosenberg LM, Girotra M. Cancer immunotherapy-immune checkpoint blockade and associated endocrinopathies. Nat Rev Endocrinol. 2017;13:195-207.

55. Gu L, Khadaroo PA, Su H, Kong L, Chen L, Wang X, et al. The safety and tolerability of combined immune checkpoint inhibitors (anti-PD-1/PD-L1 plus anti-CTLA-4): a systematic review and metaanalysis. BMC Cancer. 2019;19:1-10.

56. Ott PA, Hodi FS, Robert C. CTLA-4 and PD-1/PD-L1 blockade: new immunotherapeutic modalities with durable clinical benefit in melanoma patients. Clin Cancer Res. 2013;19:5300-9.

57. Sunshine J, Taube JM. Pd-1/pd-11 inhibitors. Curr Opin Pharmacol. 2015;23:32-8.

58. McDermott D, Lebbé C, Hodi FS, Maio M, Weber JS, Wolchok JD, et al. Durable benefit and the potential for long-term survival with immunotherapy in advanced melanoma. Cancer Treat Rev. 2014;40: 1056-64.

59. McCarthy EF. The toxins of William B. Coley and the treatment of bone and soft-tissue sarcomas. Iowa Orthop J. 2006;26:154.

60. Toussaint B, Chauchet X, Wang Y, Polack B, Gouëllec AL. Live-attenuated bacteria as a cancer vaccine vector. Expert Rev Vaccines. 2013;12: 1139-54.

61. Liu J, Tran V, Leung AS, Alexander DC, Zhu B. BCG vaccines: their mechanisms of attenuation and impact on safety and protective efficacy. Hum Vaccin. 2009;5:70-8.

62. Cherry JD. Pertussis: challenges today and for the future. PLoS Pathog. 2013;9:e1003418.

63. Edwards KM, Decker MD. Pertussis vaccines. In: Plotkin's vaccines. Amsterdam: Elsevier; 2018. p. 711- 61. e16.

64. Gardlik R, Fruehauf JH. Bacterial vectors and delivery systems in cancer therapy. IDrugs. 2010;13: 701-6. 
65. Park SJ, Park S-H, Cho S, Kim D-M, Lee Y, Ko SY, et al. New paradigm for tumor theranostic methodology using bacteria-based microrobot. Sci Rep. 2013;3:1-8.

66. Park SJ, Lee YK, Cho S, Uthaman S, Park IK, Min JJ, et al. Effect of chitosan coating on a bacteria-based alginate microrobot. Biotechnol Bioeng. 2015;112: 769-76.

67. Al-Fandi M, Alshraiedeh N, Oweis R, Alshdaifat $\mathrm{H}$, Al-Mahaseneh O, Al-Tall K, et al. Novel selective detection method of tumor angiogenesis factors using living nano-robots. Sensors. 2017;17:1580.

68. Gharaibeh RZ, Jobin C. Microbiota and cancer immunotherapy: in search of microbial signals. Gut. 2019;68:385-8.

69. Gedde MM, Higgins DE, Tilney LG, Portnoy DA. Role of listeriolysin $\mathrm{O}$ in cell-to-cell spread of listeria monocytogenes. Infect Immun. 2000;68:999-1003.

70. Diaz LA Jr, Cheong I, Foss CA, Zhang X, Peters BA, Agrawal $\mathrm{N}$, et al. Pharmacologic and toxicologic evaluation of C. novyi-NT spores. Toxicol Sci. $2005 ; 88: 562-75$.

71. Raza MH, Siraj S, Arshad A, Waheed U, Aldakheel F, Alduraywish S, et al. ROS-modulated therapeutic approaches in cancer treatment. J Cancer Res Clin Oncol. 2017;143:1789-809.

72. Yu B, Yang M, Shi L, Yao Y, Jiang Q, Li X, et al. Explicit hypoxia targeting with tumor suppression by creating an "obligate" anaerobic Salmonella Typhimurium strain. Sci Rep. 2012;2:1-10.

73. Jesenberger V, Procyk KJ, Yuan J, Reipert S, Baccarini M. Salmonella-induced caspase-2 activation in macrophages: a novel mechanism in pathogenmediated apoptosis. J Exp Med. 2000;192:1035-46.

74. Luo X, Ittensohn M, Low B, Pawelek J, Li Z, Ma X, et al. Genetically modified Salmonella typhimurium inhibited growth of primary tumors and metastases. Proc Annu Meet Am Assoc Cancer Res. 1999;40:3146.

75. GmbH, V. VXM01 Plus Avelumab Combination Study in Progressive Glioblastoma. 2018. https:// clinicaltrials.gov/ct2/show/NCT03750071. Accessed 17 Oct 2021.

76. Zheng JH, Min J-J. Targeted cancer therapy using engineered Salmonella typhimurium. Chonnam Med J. 2016;52:173-84.

77. Wang C-Z, Kazmierczak RA, Eisenstark A. Strains, mechanism, and perspective: Salmonella-based cancer therapy. Int J Microbiol. 2016;2016: 5678702 .
78. Cossart P. The listeriolysin O gene: a chromosomal locus crucial for the virulence of Listeria monocytogenes. Infection. 1988;16:S157-9.

79. Coelho C, Brown L, Maryam M, Vij R, Smith DF, Burnet MC, et al. Listeria monocytogenes virulence factors, including listeriolysin $\mathrm{O}$, are secreted in biologically active extracellular vesicles. J Biol Chem. 2019;294:1202-17.

80. Flickinger JC, Rodeck U, Snook AE. Listeria monocytogenes as a vector for cancer immunotherapy: current understanding and progress. Vaccines. 2018;6:48.

81. Yang Y, Hou J, Lin Z, Zhuo H, Chen D, Zhang X, et al. Attenuated Listeria monocytogenes as a cancer vaccine vector for the delivery of CD24, a biomarker for hepatic cancer stem cells. Cell Mol Immunol. 2014;11:184-96.

82. Advaxis, Inc. Study of ADXS-503 With or Without Pembro in Subjects With Metastatic Non-Small Cell Lung Cancer. 2019. https://clinicaltrials.gov/ct2/ show/NCT03847519. Accessed 17 Oct 2021.

83. Advaxis, I. ADXS31-142 Alone and in Combination With Pembrolizumab (MK-3475) in Patients With Prostate Cancer. 2014. https://clinicaltrials.gov/ct2/ show/NCT02325557. Accessed 17 Oct 2021.

84. Singh R, Dominiecki ME, Jaffee EM, Paterson Y. Fusion to Listeriolysin $\mathrm{O}$ and delivery by Listeria monocytogenes enhances the immunogenicity of HER-2/neu and reveals subdominant epitopes in the FVB/N mouse. J Immunol. 2005;175:3663-73.

85. Wei H, Chen L, Lian G, Yang J, Li F, Zou Y, et al. Antitumor mechanisms of bifidobacteria. Oncol Lett. 2018;16:3-8.

86. Lee DK, Jang S, Kim MJ, Kim JH, Chung MJ, Kim KJ, et al. Anti-proliferative effects of Bifidobacterium adolescentis SPM0212 extract on human colon cancer cell lines. BMC Cancer. 2008;8:1-8.

87. Kim H, Oh R, Park S, Ji GE, Park MS, Kim S-E (2021) Bifidobacterium longum RAPO enhances efficacy of anti-PD-1 immunotherapy in a mouse model of triple-negative breast cancer. AACR. 81(13 Supplement). $\quad$ https://doi.org/10.1158/1538-7445. AM2021-72.

88. Umer B, Good D, Anné J, Duan W, Wei MQ. Clostridial spores for cancer therapy: targeting solid tumour microenvironment. J Toxicol. 2012;2012: 862764

89. Hoffman RM, Zhao M. Methods for the development of tumor-targeting bacteria. Expert Opin Drug Discov. 2014;9:741-50. 
90. Wang L, Wang Q, Tian X, Shi X. Learning from clostridium novyi-NT: how to defeat cancer. J Cancer Res Ther. 2018;14:1.

91. Hradicka P, Beal J, Kassayova M, Foey A, Demeckova V. A novel lactic acid bacteria mixture: macrophagetargeted prophylactic intervention in colorectal cancer management. Microorganisms. 2020;8:387.

92. Danino T, Prindle A, Kwong GA, Skalak M, Li H, Allen K, et al. Programmable probiotics for detection of cancer in urine. Sci Transl Med. 2015;7: 289ra84-ra84.

93. Cha S, Ahn B, Kim J (2008) Korea Food Research Institute, assignee Weissella cibaria 148-2 lactic bacteria for functional healthy effect and Makgeolli containing the same. Korea patent KR 1020080133488 inventors probiotic properties of lactic acid bacteria isolated from water-buffalo mozzarella cheese

94. Chowdhury S, Pu K, Nimura C, Castro S, Coker C, Hinchliffe T, et al. (2020) Programmable bacteria induce durable tumor regression and systemic antitumor immunity. AACR. 80(16 Supplement). https://doi.org/10.1158/1538-7445.AM2020-1074.

95. Chowdhury S, Castro S, Coker C, Hinchliffe TE, Arpaia N, Danino T. Programmable bacteria induce durable tumor regression and systemic antitumor immunity. Nat Med. 2019;25:1057-63.

96. Sharma AK, Dhasmana N, Dubey N, Kumar N, Gangwal A, Gupta M, et al. Bacterial virulence factors: secreted for survival. Indian J Microbiol. 2017;57:1-10.

97. Samec M, Liskova A, Koklesova L, Samuel SM, Murin R, Zubor P, et al. The role of plant-derived natural substances as immunomodulatory agents in carcinogenesis. J Cancer Res Clin Oncol. 2020;146: 3137-54. https://doi.org/10.1007/s00432-02003424-2.

98. Wei J, Liu R, Hu X, Liang T, Zhou Z, Huang Z. MAPK signaling pathway-targeted marine compounds in cancer therapy. J Cancer Res Clin Oncol. 2021;147: 3-22. https://doi.org/10.1007/s00432-020-03460-y.

99. Information NCfB (2021) PubChem compound summary for CID 42640846, Arenamide A

100. Asolkar RN, Freel KC, Jensen PR, Fenical W, Kondratyuk TP, Park E-J, et al. Arenamides A-C, cytotoxic NFкB inhibitors from the marine actinomycete Salinispora arenicola. J Nat Prod. 2009;72:396-402.

101. Asolkar RN, Kirkland TN, Jensen PR, Fenical W. Arenimycin, an antibiotic effective against rifampin-and methicillin-resistant Staphylococcus aureus from the marine actinomycete Salinispora arenicola. J Antibiot. 2010;63:37-9.

102. Yang L, Tan R-x, Wang Q, Huang W-y, Yin Y-X. Antifungal cyclopeptides from Halobacillus litoralis YS3106 of marine origin. Tetrahedron Lett. 2002; 43:6545-8.

103. Karpiński TM, Adamczak A. Anticancer activity of bacterial proteins and peptides. Pharmaceutics. 2018;10:54.

104. Tareq FS, Kim JH, Lee MA, Lee H-S, Lee Y-J, Lee JS, et al. Ieodoglucomides $\mathrm{A}$ and $\mathrm{B}$ from a marinederived bacterium Bacillus licheniformis. Org Lett. 2012;14:1464-7.

105. Olano C, Méndez C, Salas JA. Antitumor compounds from marine actinomycetes. Mar Drugs. $2009 ; 7: 210-48$.

106. Cho JY, Williams PG, Kwon HC, Jensen PR, Fenical W. Lucentamycins $A-D$, cytotoxic peptides from the marine-derived actinomycete Nocardiopsis lucentensis. J Nat Prod. 2007;70:1321-8.

107. Soleimanpour S, Hasanian SM, Avan A, Yaghoubi A, Khazaei M. Bacteriotherapy in gastrointestinal cancer. Life scie. 2020;254:117754. https://doi.org/10. 1016/j.lfs.2020.117754.

108. Information NCfB (2021) PubChem compound summary for CID 146682041, Lucentamycin A

109. Kemp GC. Total solid-phase synthesis of the mixirins; antitumour cyclic lipopeptides. United Kingdom: University of London, University College London; 2011.

110. Zhang H, Fang D-C, Wang R-Q, Yang S-M, Liu H-F, Luo Y-H. Effect of Helicobacter pylori infection on expressions of Bcl-2 family members in gastric adenocarcinoma. World J Gastroenterol. 2004;10: 227.

111. Mondol MAM, Shin HJ, Islam MT. Diversity of secondary metabolites from marine Bacillus species: chemistry and biological activity. Mar Drugs. 2013;11:2846-72.

112. Dey G, Bharti R, Sen R, Mandal M. Microbial amphiphiles: a class of promising new-generation anticancer agents. Drug Discovery Today. 2015;20: 136-46.

113. Matsuo Y, Kanoh K, Yamori T, Kasai H, Katsuta A, Adachi K, et al. Urukthapelstatin A, a novel cytotoxic substance from marine-derived Mechercharimyces asporophorigenens YM11-542. J Antibiot. 2007;60:251-5. 
114. Schwenk S, Ronco C, Oberheide A, Arndt HD. Biomimetic synthesis of urukthapelstatin A by AzaWittig ring contraction. Eur J Org Chem. 2016;2016:4795-9.

115. Karpiński T, Szkaradkiewicz A, Gamian A (2013) New enterococcal anticancer peptide. 23rd European Congress of Clinical Microbiology and Infectious Diseases Berlin, Germany pp 30

116. Karpiński TM, Szkaradkiewicz AK. Anticancer peptides from bacteria. Bangladesh J Pharmacol. 2013;8:343-8.

117. Lee DG, Hahm K-S, Park Y, Kim H-Y, Lee W, Lim $\mathrm{S}-\mathrm{C}$, et al. Functional and structural characteristics of anticancer peptide Pep27 analogues. Cancer Cell Int. 2005;5:1-14.

118. Rodrigues G, Silva GGO, Buccini DF, Duque HM, Dias SC, Franco OL. Bacterial proteinaceous compounds with multiple activities toward cancers and microbial infection. Front Microbiol. 2019;10:1690.

119. Hu C, Chen X, Huang Y, Chen Y. Synergistic effect of the pro-apoptosis peptide kla-TAT and the cationic anticancer peptide HPRP-A1. Apoptosis. 2018;23:132-42.

120. Yaghoubi A, Khazaei M, Ghazvini K, Movaqar A, Avan A, Hasanian SM, et al. Peptides with dual antimicrobial-anticancer activity derived from the $\mathrm{N}$-terminal region of $\mathrm{H}$ pylori ribosomal protein $\mathrm{L} 1$ (RpL1). Int J Pept Res Ther. 2021;27:1-11.

121. Lee HJ, Kim HY. Lantibiotics, class I bacteriocins from the genus Bacillus. J Microbiol Biotechnol. 2011;21:229-35.

122. Kawai Y, Kemperman R, Kok J, Saito T. The circular bacteriocins gassericin A and circularin A. Curr Protein Pept Sci. 2004;5:393-8.

123. Barnes BB, Steindorf K, Hein R, Flesch-Janys D, Chang-Claude J. Population attributable risk of invasive postmenopausal breast cancer and breast cancer subtypes for modifiable and non-modifiable risk factors. Cancer Epidemiol. 2011;35:345-52.

124. Paiva AD, de Oliveira MD, de Paula SO, BaracatPereira MC, Breukink E, Mantovani HC. Toxicity of bovicin HC5 against mammalian cell lines and the role of cholesterol in bacteriocin activity. Microbiology. 2012;158:2851-8.

125. Paiva AD, Irving N, Breukink E, Mantovani HC. Interaction with lipid II induces conformational changes in bovicin HC5 structure. Antimicrob Agents Chemother. 2012;56:4586-93.

126. Goudarzi F, Asadi A, Afsharpour M, Jamadi RH. In vitro characterization and evaluation of the cytotoxicity effects of nisin and nisin-loaded PLAPEG-PLA nanoparticles on gastrointestinal (AGS and KYSE-30), hepatic (HepG2) and blood (K562) cancer cell lines. AAPS PharmSciTech. 2018;19: 1554-66.

127. Zainodini N, Hassanshahi G, Hajizadeh M, FalahatiPour SK, Mahmoodi M, Mirzaei MR. Nisin induces cytotoxicity and apoptosis in human asterocytoma cell line (SW1088). Asian Pacific J Cancer Prev: APJCP. 2018;19:2217.

128. Norouzi Z, Salimi A, Halabian R, Fahimi H. Nisin, a potent bacteriocin and anti-bacterial peptide, attenuates expression of metastatic genes in colorectal cancer cell lines. Microb Pathog. 2018;123: 183-9.

129. Hosseini SS, Hajikhani B, Faghihloo E, Goudarzi H. Increased expression of caspase genes in colorectal cancer cell line by nisin. Arch Clin Infect Dis. 2020;15:e97734.

130. Raccach M. Pediococcus. Encyclopedia of Food Microbiology (Second Edition). Academic Press, Elsevier; 2014. pp. 1-5. ISBN 9780123847331. https://doi.org/10.1016/B978-0-12-384730-0. 00247-0.

131. Villarante KI, Elegado FB, Iwatani S, Zendo T, Sonomoto K, de Guzman EE. Purification, characterization and in vitro cytotoxicity of the bacteriocin from Pediococcus acidilactici K2a2-3 against human colon adenocarcinoma (HT29) and human cervical carcinoma (HeLa) cells. World J Microbiol Biotechnol. 2011;27:975-80.

132. Ray B, Hoover DG. Pediocins. In: Bacteriocins of lactic acid bacteria. Amsterdam: Elsevier; 1993. p. 181-210.

133. Kaur B, Balgir P, Mittu B, Chauhan A, Kumar B, Garg $\mathrm{N}$. Isolation and In vitro characterization of antiGardnerella vaginalis bacteriocin producing Lactobacillus fermentum HV6b isolated from human vaginal ecosystem. Int $\mathrm{J}$ of Fundam Appl Sci. 2012;1:41.

134. Kaur B, Balgir PP, Mittu B, Kumar B, Garg N. Biomedical applications of fermenticin HV6b isolated from Lactobacillus fermentum HV6b MTCC10770. BioMed Res Int. 2013;2013:168438.

135. Šmarda J, Obdržálek V, Táborský I, Mach J. The cytotoxic and cytocidal effect of colicin E3 on mammalian tissue cells. Folia Microbiol. 1978;23: 272-7.

136. Gilbert R. Pore-forming toxins. Cell Mol Life Sci CMLS. 2002;59:832-44. 
137. Kaur S, Kaur S. Bacteriocins as potential anticancer agents. Front Pharmacol. 2015;6:272.

138. Sano Y, Matsui H, Kobayashi M, Kageyama M. Molecular structures and functions of pyocins S1 and S2 in Pseudomonas aeruginosa. J Bacteriol. 1993;175:2907-16.

139. Watanabe T, Saito H. Cytotoxicity of pyocin S2 to tumor and normal cells and its interaction with cell surfaces. Biochim Biophys Acta (BBA)-Gen Subj. 1980;633:77-86.

140. Abdi-Ali A, Worobec E, Deezagi A, Malekzadeh F. Cytotoxic effects of pyocin S2 produced by Pseudomonas aeruginosa on the growth of three human cell lines. Can J Microbiol. 2004;50:375-81.

141. Murphy JR. Mechanism of diphtheria toxin catalytic domain delivery to the eukaryotic cell cytosol and the cellular factors that directly participate in the process. Toxins. 2011;3:294-308.

142. Martarelli D, Pompei P, Mazzoni G. Inhibition of adrenocortical carcinoma by diphtheria toxin mutant CRM197. Chemotherapy. 2009;55:425-32.

143. Lewis DJ, Dao H Jr, Nagarajan P, Duvic M. Primary cutaneous anaplastic large-cell lymphoma: complete remission for 13 years after denileukin diftitox. JAAD Case Rep. 2017;3:501.

144. Voth DE, Ballard JD. Clostridium difficile toxins: mechanism of action and role in disease. Clin Microbiol Rev. 2005;18:247-63.

145. Zhang Y, Li Y, Li H, Chen W, Liu W. Clostridium difficile toxin $B$ recombinant protein inhibits tumor growth and induces apoptosis through inhibiting $\mathrm{Bcl}-2$ expression, triggering inflammatory responses and activating C-erbB-2 and Cox-2 expression in breast cancer mouse model. Biomed Pharmacother. 2018;101:391-8.

146. Lingwood CA, Mahfoud R. Bacterial toxins and their carbohydrate receptors at the host-pathogen interface. In: Microbial glycobiology. Amsterdam: Elsevier; 2010. p. 599-621.

147. Bhattacharjee RN, Park K-S, Uematsu S, Okada K, Hoshino K, Takeda K, et al. Escherichia coli verotoxin 1 mediates apoptosis in human HCT116 colon cancer cells by inducing overexpression of the GADD family of genes and S phase arrest. FEBS Lett. 2005;579:6604-10.

148. Pollack M. The role of exotoxin A in Pseudomonas disease and immunity. Rev infect dis. 1983;5:S979S984.

149. Holtsberg FW, Ensor CM, Steiner MR, Bomalaski JS, Clark MA. Poly (ethylene glycol)(PEG) conjugated arginine deiminase: effects of PEG formulations on its pharmacological properties. J Control Release. 2002;80:259-71.

150. Kim RH, Coates JM, Bowles TL, McNerney GP, Sutcliffe J, Jung JU, et al. Arginine deiminase as a novel therapy for prostate cancer induces autophagy and caspase-independent apoptosis. Can Res. 2009;69: 700-8.

151. Baban CK, Cronin M, O'Hanlon D, O'Sullivan GC, Tangney M. Bacteria as vectors for gene therapy of cancer. Bioengineered bugs. 2010;1:385-94.

152. Amer MH. Gene therapy for cancer: present status and future perspective. Mol Cell Ther. 2014;2:27.

153. Morales A, Eidinger D, Bruce A. Intracavitary Bacillus Calmette-Guerin in the treatment of superficial bladder tumors. J Urol. 2002;167:891-4.

154. Sieow BF, Wun KS, Yong WP, Hwang IY, Chang MW. Tweak to Treat: Reprogramming Bacteria for Cancer Treatment. Trends Cancer. 2021;7(5): 447-64. https://doi.org/10.1016/j.trecan.2020.11. 004.

155. Alexandroff AB, Jackson AM, O’Donnell MA, James K. BCG immunotherapy of bladder cancer: 20 years on. The Lancet. 1999;353:1689-94.

156. Maciag PC, Radulovic S, Rothman J. The first clinical use of a live-attenuated Listeria monocytogenes vaccine: a phase I safety study of Lm-LLO-E7 in patients with advanced carcinoma of the cervix. Vaccine. 2009;27:3975-83.

157. Le DT, Brockstedt DG, Nir-Paz R, Hampl J, Mathur S, Nemunaitis J, et al. A live-attenuated Listeria vaccine (ANZ-100) and a live-attenuated Listeria vaccine expressing mesothelin (CRS-207) for advanced cancers: phase I studies of safety and immune induction. Clin Cancer Res. 2012;18:858-68.

158. Wood LM, Guirnalda PD, Seavey MM, Paterson Y. Cancer immunotherapy using Listeria monocytogenes and listerial virulence factors. Immunol Res. 2008;42:233-45.

159. Fujimori M. Anaerobic bacteria as a gene delivery system for breast cancer therapy. Nihon rinsho. Jpn J Clin Med. 2008;66:1211-8.

160. Fujimori M. Genetically engineered Bifidobacterium as a drug delivery system for systemic therapy of metastatic breast cancer patients. Breast Cancer. 2006;13:27-31.

161. Sasaki T, Fujimori M, Hamaji Y, Hama Y, Ki I, Amano J, et al. Genetically engineered Bifidobacterium longum for tumor-targeting enzyme- 
prodrug therapy of autochthonous mammary tumors in rats. Cancer Sci. 2006;97:649-57.

162. Cronin M, Stanton R, Francis K, Tangney M. Bacterial vectors for imaging and cancer gene therapy: a review. Cancer Gene Ther. 2012;19:731-40.

163. Denny WA. Tumor-activated prodrugs-a new approach to cancer therapy. Cancer Invest. 2004;22: 604-19.

164. Hu J, Chen C, Zhang S, Zhao X, Xu H, Zhao X, et al. Designed antimicrobial and antitumor peptides with high selectivity. Biomacromol. 2011;12: 3839-43.

165. Tørfoss V, Isaksson J, Ausbacher D, Brandsdal BO, Flaten GE, Anderssen T, et al. Improved anticancer potency by head-to-tail cyclization of short cationic anticancer peptides containing a lipophilic $\beta 2$, 2-amino acid. J Pept Sci. 2012;18:609-19.

166. Dang LH, Bettegowda C, Huso DL, Kinzler KW, Vogelstein B. Combination bacteriolytic therapy for the treatment of experimental tumors. Proc Natl Acad Sci. 2001;98:15155-60.

167. Hatefi A, Canine BF. Perspectives in vector development for systemic cancer gene therapy. Gene Ther Mol Biol. 2009;13:15.

168. Patyar S, Joshi R, Byrav DP, Prakash A, Medhi B, Das B. Bacteria in cancer therapy: a novel experimental strategy. J Biomed Sci. 2010;17:21. 